\title{
Coordination and binding geometry of methyl-coenzyme $M$ in the red1m state of methyl-coenzyme $M$ reductase
}

\author{
Dariush Hinderberger $\cdot$ Sieglinde Ebner $\cdot$ Stefan Mayr $\cdot$ \\ Bernhard Jaun · Markus Reiher · Meike Goenrich · \\ Rudolf K. Thauer $\cdot$ Jeffrey Harmer
}

Received: 16 April 2008/Accepted: 27 July 2008/Published online: 19 August 2008

(C) The Author(s) 2008. This article is published with open access at Springerlink.com

\begin{abstract}
Methane formation in methanogenic Archaea is catalyzed by methyl-coenzyme $\mathrm{M}$ reductase (MCR) and takes place via the reduction of methyl-coenzyme $\mathrm{M}$ $\left(\mathrm{CH}_{3}-\mathrm{S}-\mathrm{CoM}\right)$ with coenzyme B (HS-CoB) to methane and the heterodisulfide CoM-S-S-CoB. MCR harbors the nickel porphyrinoid coenzyme $\mathrm{F}_{430}$ as a prosthetic group, which has to be in the $\mathrm{Ni}(\mathrm{I})$ oxidation state for the enzyme to be active. To date no intermediates in the catalytic cycle of $\mathrm{MCR}_{\text {red1 }}$ (red for reduced $\mathrm{Ni}$ ) have been identified. Here, we report a detailed characterization of $\mathrm{MCR}_{\mathrm{red} 1 \mathrm{~m}}$ ( " $\mathrm{m}$ " for methyl-coenzyme M), which is the complex of $\mathrm{MCR}_{\text {redla }}$ ("a" for absence of substrate) with $\mathrm{CH}_{3}-\mathrm{S}-\mathrm{CoM}$. Using continuous-wave and pulse electron paramagnetic resonance spectroscopy in combination with selective isotope
\end{abstract}

Electronic supplementary material The online version of this article (doi:10.1007/s00775-008-0417-0) contains supplementary material, which is available to authorized users.

\section{J. Harmer $(\bowtie)$}

Department of Chemistry,

Centre for Advanced Electron Spin Resonance (CAESR),

University of Oxford,

South Parks Road,

Oxford OX1 3QR, UK

e-mail: jeffrey.harmer@chem.ox.ac.uk

S. Ebner · S. Mayr · B. Jaun $(\bowtie)$

Laboratorium für Organische Chemie,

ETH Zürich,

Wolfgang-Pauli-Strasse 10,

8093 Zurich, Switzerland

e-mail: jaun@org.chem.ethz.ch

D. Hinderberger

Max-Planck-Institut für Polymerforschung,

Ackermannweg 10,

55128 Mainz, Germany

e-mail: hinderberger@mpip-mainz.mpg.de labeling $\left({ }^{13} \mathrm{C}\right.$ and $\left.{ }^{2} \mathrm{H}\right)$ of $\mathrm{CH}_{3}-\mathrm{S}-\mathrm{CoM}$, it is shown that $\mathrm{CH}_{3}$-S-CoM binds in the active site of MCR such that its thioether sulfur is weakly coordinated to the $\mathrm{Ni}(\mathrm{I})$ of $\mathrm{F}_{430}$. The complex is stable until the addition of the second substrate, HS-CoB. Results from EPR spectroscopy, along with quantum mechanical calculations, are used to characterize the electronic and geometric structure of this complex, which can be regarded as the first intermediate in the catalytic mechanism.

Keywords Methyl-coenzyme M reductase - MCR . Nickel enzyme $\cdot$ Catalytic cycle $\cdot$ Factor $\mathrm{F}_{430}$

\section{Abbreviations \\ $\mathrm{CH}_{3}$-S-CoM Methyl-coenzyme M \\ ENDOR Electron nuclear double resonance \\ EPR Electron paramagnetic resonance \\ HS-CoB Coenzyme B}

\section{Reiher}

Laboratorium für Physikalische Chemie,

ETH Zürich,

Wolfgang-Pauli-Strasse 10,

8093 Zurich, Switzerland

M. Goenrich · R. K. Thauer

Max-Planck-Institut für Terrestrische Mikrobiologie,

Karl-von-Frisch-Straße,

35043 Marburg, Germany 


\begin{tabular}{|c|c|}
\hline & \\
\hline IYSC & Hyperfine sublevel correlation spectroscopy \\
\hline ICR & Methyl-coenzyme $\mathrm{M}$ reductase \\
\hline $\mathrm{ICR}_{\mathrm{BPS}}$ & $\begin{array}{l}\text { MCR after the addition of 3-bromopropane } \\
\text { sulfonate }\end{array}$ \\
\hline $\mathrm{ICR}_{\mathrm{BrMe}}$ & MCR after the addition of methyl bromide \\
\hline $\mathrm{CR}_{\mathrm{IMe}}$ & ter the addition of methyl iodide \\
\hline $\mathrm{CR}_{\mathrm{ox}}$ & $\begin{array}{l}\text { MCR exhibiting the ox } 1 \text {, ox } 2 \text { or ox } 3 \text { EPR } \\
\text { spectra }\end{array}$ \\
\hline $\mathrm{MCR}_{\text {red1 }}$ & $\begin{array}{l}\text { Active MCR exhibiting one of the red } 1 \\
\text { EPR spectra }\end{array}$ \\
\hline $\mathrm{MCR}_{\text {red1a }}$ & MCR-red 1 in the absence of any substrates \\
\hline $\mathrm{MCR}_{\mathrm{re}}$ & $\begin{array}{l}\text { MCR-red1 in the presence of } 10 \mathrm{mM} \\
\text { coenzyme } \mathrm{M}\end{array}$ \\
\hline $\mathrm{MCR}_{\text {red } 1 \mathrm{~m}}$ & $\begin{array}{l}\text { MCR-red1 in the presence of } 10 \mathrm{mM} \\
\text { methyl-coenzyme } \mathrm{M}\end{array}$ \\
\hline $\mathrm{MCR}_{\text {red2 }}$ & MCR exhibiting the two red2 EPR spectra \\
\hline $\mathrm{MCR}_{\text {red2a }}$ & $\begin{array}{l}\text { MCR exhibiting the axial red2 EPR } \\
\text { spectrum }\end{array}$ \\
\hline $\mathrm{CCE}$ & $\begin{array}{l}\text { MCR exhibiting the rhombic red2 EPR } \\
\text { spectrum }\end{array}$ \\
\hline
\end{tabular}

\section{Introduction}

Methyl-coenzyme M reductase (MCR) catalyzes the key step of methanogenesis in Archaea, namely the reduction of methyl-coenzyme $\mathrm{M}\left(\mathrm{CH}_{3}-\mathrm{S}-\mathrm{CoM}\right)$ with coenzyme B
(HS-CoB) to methane and the heterodisulfide CoM-S-SCoB (Eq. 1, Structure 1):

$$
\begin{aligned}
& \mathrm{CH}_{3} \mathrm{~S}-\mathrm{CoM}+\mathrm{HS}-\mathrm{CoB} \rightarrow \mathrm{CH}_{4}+\mathrm{CoM}-\mathrm{S}-\mathrm{S}-\mathrm{CoB} \\
& \Delta G^{0 \prime}=-30 \mathrm{~kJ} \mathrm{~mol}^{-1} .
\end{aligned}
$$

Methanogenic Archaea are found in strictly anoxic habitats such as wetlands, sewage sites or the rumens and guts of animals, and they gain the energy necessary for ATP synthesis by producing methane from substrates such as $\mathrm{H}_{2} / \mathrm{CO}_{2}$, acetate, formate or methanol $[1,2]$. This process is responsible for the largest part of the annual emission (estimated $5 \times 10^{8}$ tons per year) of this very effective greenhouse gas into the atmosphere. All methanogens contain MCR, and X-ray crystallography of inactive $\mathrm{Ni}$ (II) forms shows that the enzyme has two identical active sites, each containing one molecule of coenzyme $F_{430}$ (Structure 1) [3]. In the active state, designated $\mathrm{MCR}_{\text {red1 }}$, the central metal is in the $\mathrm{Ni}(\mathrm{I})$ valence state and its EPR spectrum is characteristic of a $d^{9} S=1 / 2$ species with the unpaired electron in a molecular orbital of predominantly nickel $d_{x^{2}-y^{2}}$ character [4]. The active site of MCR is structured such that, of the two substrates, $\mathrm{CH}_{3}-\mathrm{S}$ CoM has to bind first. The MCR states of relevance for this paper are summarized in Chart 1.

The catalytic mechanism of the reduction (Eq. 1) at the nickel center is widely disputed [5-13]. In essence, two mechanisms mainly differing in the nature of the initial cleavage of the sulfur-carbon bond of $\mathrm{CH}_{3}-\mathrm{S}-\mathrm{CoM}$ are currently discussed. In mechanism "A," proposed by
Structure 1 Left: schematic representation of coenzyme $\mathrm{F}_{430}, \mathrm{CH}_{3}-\mathrm{S}-\mathrm{CoM}, \mathrm{Gln}^{\alpha^{\prime} 147}$ from the alpha subunit of MCR [3], and the orientation of the $g_{3}$-axis. Right: coenzyme $\mathrm{M}$ (HS-CoM), methyl-coenzyme M $\left(\mathrm{CH}_{3}-\mathrm{S}-\mathrm{CoM}\right)$, and coenzyme B $(H S-C o B)$

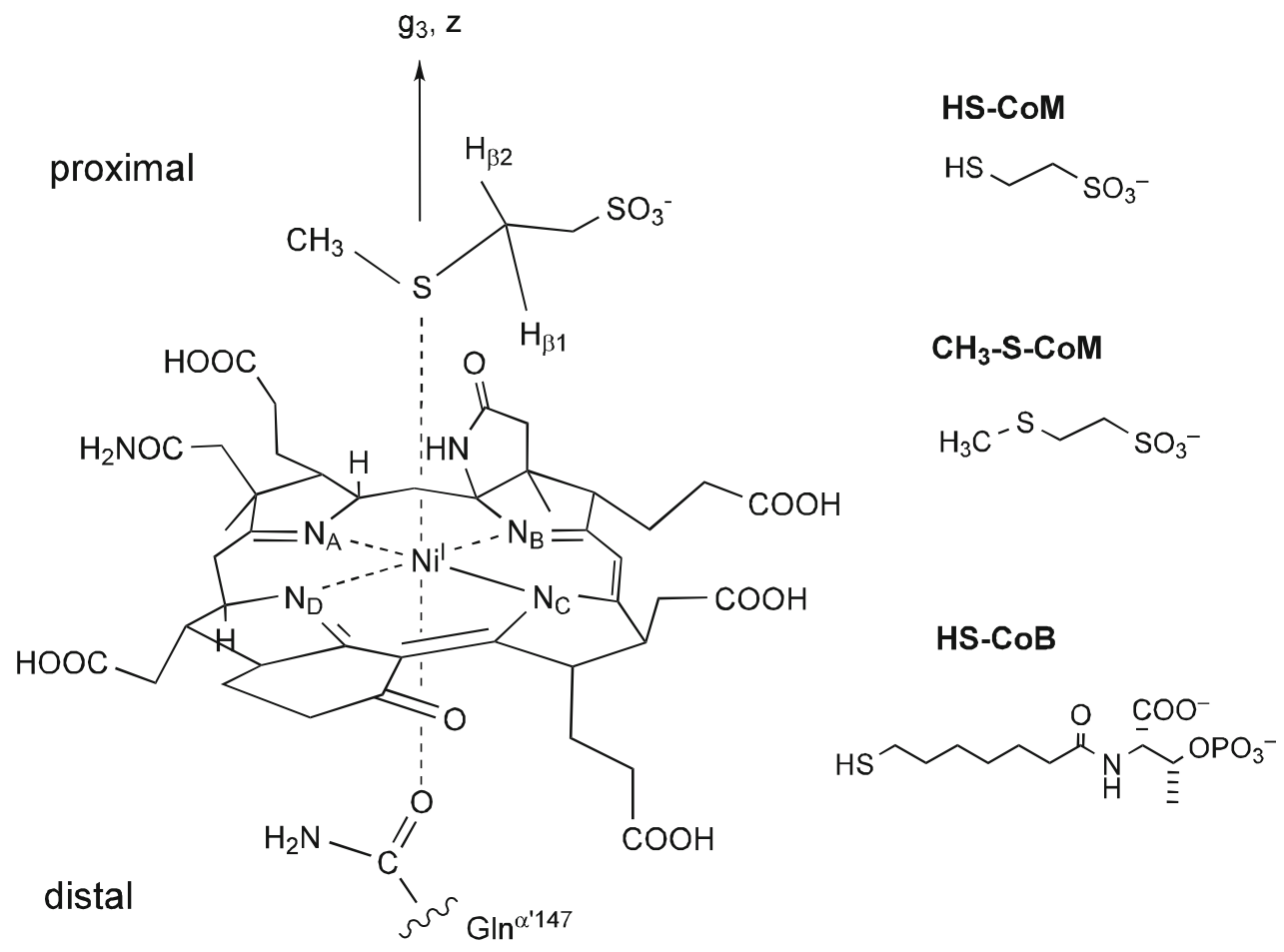


Chart 1 Chart showing different EPR-active forms of MCR and their interconversion. Catalysis by MCR is believed to start with $\mathrm{MCR}_{\text {red 1a, }}$, where the cofactor $\mathrm{F}_{430}$ has the $\mathrm{Ni}(\mathrm{I})$ oxidation state and the absence of a proximal substrate is denoted by " $a$." Methylcoenzyme $\mathrm{M}\left(\mathrm{CH}_{3}-\mathrm{S}-\mathrm{CoM}\right)$ is added to form the $\mathrm{MCR}_{\text {red } 1 \mathrm{~m}}$ state, which is highlighted in red and is the main subject of this report. From this state, methane is produced by the addition of HS-CoB
$M R_{\text {ox }}$ species

or EPR-silent forms

$\uparrow$

<oxidation>

$\mathrm{MCR}_{\text {red1 }}$ [22]

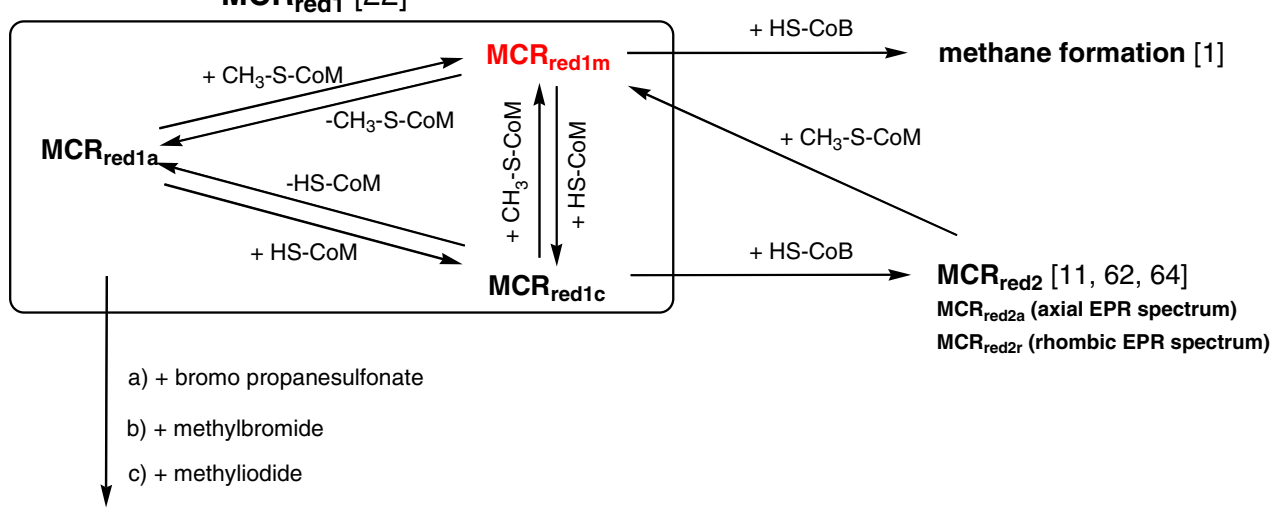

Ni-alkyl species:

a) $\mathbf{M C R}_{\mathrm{BPS}}[14,15]$

b) $\mathrm{MCR}_{\mathrm{BrMe}}[16]$

c) $M C R_{I M e}[17]$
Pelmenschikov et al. [5, 6] on the basis of DFT calculations, the $\mathrm{Ni}(\mathrm{I})$ center is assumed to attack the thioether sulfur of $\mathrm{CH}_{3}-\mathrm{S}-\mathrm{CoM}$, generating $\mathrm{CH}_{3}$ and the thiolate complex CoM-S-Ni(II)F 430 as intermediates (see Fig. 8).

According to mechanism " $\mathrm{B}$," the $\mathrm{Ni}(\mathrm{I})$ center initially acts as a nucleophile, attacking methyl-coenzyme $\mathrm{M}$ at the carbon of the $\mathrm{CH}_{3}-\mathrm{S}$ group, generating a $\mathrm{CH}_{3}-\mathrm{Ni}(\mathrm{III}) \mathrm{F}_{430}$ intermediate and HS-CoM [1, 9-12]. Recent findings indicate that such a species can exist: 3-bromopropane sulfonate was shown to react with the active enzyme $\mathrm{MCR}_{\text {red1 }}$ to give ${ }^{-} \mathrm{O}_{3} \mathrm{~S}\left(\mathrm{CH}_{2}\right)_{3}-\mathrm{Ni}(\mathrm{III}) \mathrm{F}_{430}{ }^{+}$and $\mathrm{Br}^{-}$, while $\mathrm{CH}_{3} \mathrm{Br}$ and $\mathrm{CH}_{3} \mathrm{I}$ react with $\mathrm{MCR}_{\text {red1 }}$ to form $\mathrm{CH}_{3}-\mathrm{Ni}(\mathrm{III}) \mathrm{F}_{430}{ }^{+}$in the active site [14-17], with $\mathrm{Br}^{-} / \mathrm{I}^{-}$as the leaving group. Additional evidence is provided by the reaction of free $\mathrm{Ni}(\mathrm{I}) \mathrm{F}_{430}$ derivatives with electrophilic methyl donors such as methyl-dialkylsulfonium ions and methyl halides [16, 17]. These mechanistic studies, as well as the fact that methane formation proceeds under inversion of stereoconfiguration, are consistent with mechanism "B," and $\mathrm{CH}_{3}-\mathrm{Ni}(\mathrm{III}) \mathrm{L}$ species have been postulated as intermediates on the basis of pulse radiolytic studies with simpler nickel model complexes, while a model close to the postulated $\mathrm{CH}_{3}-$ $\mathrm{Ni}(\mathrm{III}) \mathrm{F}_{430}$ was found in a theoretical study to be a minimum on the hypersurface with a $\left(d_{x y}\right)^{2}\left(d_{x z}\right)^{2}\left(d_{y z}\right)^{2}\left(d_{x^{2}-y^{2}}\right)^{1}$ ground-state configuration $[18,19]$. In addition, $\mathrm{CH}_{3}-$ $\mathrm{Ni}(\mathrm{II}) \mathrm{F}_{430}$ derivatives have been generated in situ and characterized spectroscopically [20].

Recently, a third type of reaction mechanism has been proposed by Duin and McKee [21] based on DFT calculations.
In their study, the initial step is a protonation of $\mathrm{Ni}(\mathrm{I}) \mathrm{F}_{430}$, which is followed by the anchoring of $\mathrm{CH}_{3}$-S-CoM to the nickel via sulfur, and the rate-determining step is a subsequent oxidative addition. The transition state consists of a complex in which the methyl group and the sulfur of S-CoM are bound to the central nickel at the same time. For the sake of brevity we call this mechanism, which has features from both mechanisms "A" and "B," mechanism "C."

To date no chemical intermediates for Eq. 1 have been isolated and characterized, for example by freeze-quench experiments. It is known that the addition of the substrate $\mathrm{CH}_{3}$-S-CoM to active $\mathrm{MCR}_{\text {red1a }}$ ("a" for absence of substrates) results in the formation of a species with a distinguishable CW EPR spectrum. This species, which has been named $\mathrm{MCR}_{\text {red1m }}$ ("m" for methyl-coenzyme $\mathrm{M}$ as substrate) according to $\mathrm{MCR}_{\text {red } 1 \mathrm{a}} \underset{-\mathrm{CH}_{3}-\mathrm{SCoM}}{\stackrel{+\mathrm{CH}_{3}-\mathrm{SCoM}}{\rightleftarrows}} \mathrm{MCR}_{\text {red } 1 \mathrm{~m}}$, is stable until the addition of the second substrate HS-CoB [22].

Here, we report a detailed characterization of $\mathrm{MCR}_{\text {red } 1 \mathrm{~m}}$ which shows that this state can be viewed as the first intermediate formed in the catalytic cycle of methylcoenzyme $\mathrm{M}$ reductase. Using pulse and continuous-wave (CW) electron paramagnetic resonance (EPR) spectroscopy in combination with selective isotope labeling $\left({ }^{13} \mathrm{C}\right.$ and $\left.{ }^{2} \mathrm{H}\right)$ of $\mathrm{CH}_{3}-\mathrm{S}-\mathrm{CoM}$, and aided by quantum mechanical calculations, we find that there is weak coordination between $\mathrm{Ni}(\mathrm{I})$ and the thioether $\mathrm{S}$ of $\mathrm{CH}_{3}-\mathrm{S}-\mathrm{CoM}$. This surprising result is contrary to chemical intuition and experimental 
evidence showing that free $\mathrm{Ni}(\mathrm{I}) \mathrm{F}_{430 \mathrm{M}}$ (pentamethylester of $\mathrm{F}_{430}$ ) in acetonitrile neither reacts with nor coordinates to $\mathrm{CH}_{3}$-S-CoM. Also, an X-ray absorption spectroscopy study of $\mathrm{MCR}_{\text {red1m }}$ has shown that simulation of the spectra does not require the presence of a sulfur ligand, suggesting that $\mathrm{CH}_{3}-\mathrm{S}-\mathrm{CoM}$ is not coordinated via its thioether sulfur atom to nickel in detectable amounts [23].

\section{Materials and methods}

\section{Methanothermobacter marburgensis}

Methanothermobacter marburgensis is the strain deposited under DSM 2133 in the Deutsche Sammlung von Mikroorganismen und Zellkulturen (Braunschweig). Coenzyme M (2-mercaptoethanesulfonate) was obtained from Fluka (Buchs, Switzerland); 2-(methylsulfanyl)ethanesulfonate (methyl-coenzyme M) was synthesized from coenzyme M by methylation with methyl iodide (Fluka). According to

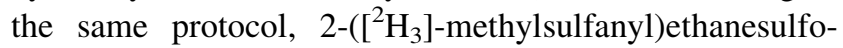

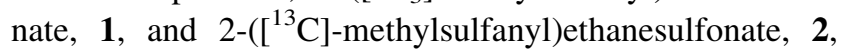
were synthesized from their corresponding iodides. Sodium methanolate $(0.335 \mathrm{M})$ was prepared by dissolving $1.58 \mathrm{~g}$ of $\mathrm{Na}$ in $100 \mathrm{~mL} \mathrm{MeOH}$ (distilled over $\mathrm{Mg}, \mathrm{I}_{2}$ ) under nitrogen. $\left[{ }^{2} \mathrm{H}_{3}\right]$-methyl iodide was obtained from Dr. Glaser AG (Basel, Switzerland), and $\left[{ }^{13} \mathrm{C}\right]$-methyl iodide from CIL (Cambridge Isotope Laboratories, Andover, MA, USA). All other routine chemicals were obtained from Fluka, Aldrich (Milwaukee, WI, USA), JT Baker (Phillipsburg, NJ, USA) and Merck (Darmstadt, Germany), and were used without further purification.

\section{Purification of active MCR}

M. marburgensis was grown at $65^{\circ} \mathrm{C}$ in a $13 \mathrm{~L}$ glass fermenter (New Brunswick, Edison, NJ, USA) containing $10 \mathrm{~L}$ mineral medium stirred at 1,200 rpm and gassed with $80 \% \mathrm{H}_{2} / 20 \% \mathrm{CO}_{2} / 0.1 \% \mathrm{H}_{2} \mathrm{~S}$ at a rate of $1,200 \mathrm{~mL} / \mathrm{min}$ [22]. When an $\Delta \mathrm{OD}_{578}$ of 4.5 was reached, the gas supply was switched to $100 \% \mathrm{H}_{2}$ for $30 \mathrm{~min}$. Under these conditions, the intracellular methyl-coenzyme $M$ reductase was reduced, as revealed by measuring the EPR signals of $\mathrm{MCR}_{\mathrm{red} 1}$ and $\mathrm{MCR}_{\mathrm{red} 2}$ shown by the intact cells [24]. After $30 \mathrm{~min}$, the cells were cooled to $10{ }^{\circ} \mathrm{C}$ within $10 \mathrm{~min}$ under continuous gassing with $100 \% \mathrm{H}_{2}$ and harvested anaerobically by centrifugation using a flow-through centrifuge (Hettich, Kirchlengern, Germany; centrifuge $17 \mathrm{RS}$ ). Approximately $70 \mathrm{~g}$ of wet cells were obtained. Only the MCR isoenzyme I was purified from these cells [25, 26]. All steps of the purification were performed in the presence of $10 \mathrm{mM}$ coenzyme $\mathrm{M}$ and in an anaerobic chamber (Coy Instruments, Ann Arbor, MI, USA) filled with 95\% $\mathrm{N}_{2} / 5 \%$
$\mathrm{H}_{2}$ as described previously [22]. During purification the enzyme lost its red2-type signal due to the removal of coenzyme B. In one purification, $150 \mathrm{mg}$ of active MCR in the red1c state (in 3-4 ml) were generally obtained. The spin concentration per mol $\mathrm{F}_{430}$ was higher than 0.8 . To obtain $\mathrm{MCR}_{\text {red1a }}$, the purified $\mathrm{MCR}_{\text {red1c }}$ was washed free of coenzyme $\mathrm{M}$ with $50 \mathrm{mM}$ Tris/ $\mathrm{HCl} \mathrm{pH} 7.6$ by ultrafiltration with Amicon Ultra centrifugal filter devices with a $100 \mathrm{kDa}$ cut-off (Millipore, Bedford, MA). The spin concentration per mole $\mathrm{F}_{430}$ generally decreased to values of between 0.6 and 0.8 during the washing procedure. $\mathrm{MCR}_{\text {red1a }}$ was converted to $\mathrm{MCR}_{\text {red1m }}$ through the addition of methyl-coenzyme $\mathrm{M}\left({ }^{13} \mathrm{CH}_{3}-\mathrm{CoM}\right.$ or $\left.\mathrm{CD}_{3}-\mathrm{CoM}\right)$ to give a final concentration of $10 \mathrm{mM}$. The protein concentration was determined by using the method of Bradford [27] with bovine serum albumin (Serva, Heidelberg, Germany) used as standard or by measuring the absorbance difference for the oxidized enzyme $\left(\mathrm{MCR}_{\text {silent }}\right)$ at $420 \mathrm{~nm}$ using $\varepsilon=44,000 \mathrm{M}^{-1} \mathrm{~cm}^{-1}$ for a molecular mass of 280,000 Da. Both methods yielded almost the same results. The final concentration of protein obtained in our experiments was $0.6 \mathrm{mM}$.

Synthesis of 2-([2 $\left.\mathrm{H}_{3}\right]$-methylsulfanyl)ethanesulfonate (1) $[22]\left[\left[{ }^{2} \mathrm{H}_{3}\right]\right.$-methyl-coenzyme $\mathrm{M}\left(\mathrm{NH}_{4}{ }^{+}\right.$form) $]$

About $580 \mu \mathrm{L}$ of $\left[{ }^{2} \mathrm{H}_{3}\right]$-methyl iodide were added to a solution of $1 \mathrm{~g}$ of 2-mercaptoethanesulfonate (sodium salt; $6.09 \mathrm{mmol}$ ) in $20 \mathrm{~mL}$ of $0.335 \mathrm{M}$ sodium methanolate (6.09 mmol) at $0{ }^{\circ} \mathrm{C}$ (ice bath) and stirred at room temperature for $14 \mathrm{~h}$. The dried residue was dissolved in a small amount of water, acidified with Amberlite IR-120 to $\mathrm{pH} 1$, treated with concentrated $\mathrm{NH}_{3}(\mathrm{aq})$ to get $\mathrm{pH} 12$, and lyophilized to give $1.01 \mathrm{~g}$ of pure $\left(>99 \%{ }^{2} \mathrm{H}\right.$-labeled according to ${ }^{1} \mathrm{H}$ NMR) 1 (5.67 mmol; 97\%). ${ }^{1} \mathrm{H} \mathrm{NMR}$ $\left(\mathrm{D}_{2} \mathrm{O}, 400 \mathrm{MHz}\right) \delta 3.20-3.24(\mathrm{~m}, 2 \mathrm{H}), 2.88-2.92(\mathrm{~m}, 2 \mathrm{H})$. ${ }^{13} \mathrm{C}$ NMR $\left(\mathrm{D}_{2} \mathrm{O}, 400 \mathrm{MHz}\right) \delta 16.41$ (septet, $\left.J=21.3\right)$, 30.27, 53.40. ESI-MS: $m / z 95.3$ (11), 91.1 (26), 113.0 (38), 156.1 (46), 62.3 (48), 45.3 (84), 157.9 (100).

Synthesis of 2-([ $\left.{ }^{13} \mathrm{C}\right]$-methylsulfanyl)ethanesulfonate (2) $[28]\left[\left[{ }^{13} \mathrm{C}\right]\right.$-methyl-coenzyme $\mathrm{M}\left(\mathrm{NH}_{4}{ }^{+}\right.$form) $]$

About $1 \mathrm{~g}$ of $\left[{ }^{13} \mathrm{C}\right]$-methyl iodide $(7.0 \mathrm{mmol})$ was added to a solution of $1.148 \mathrm{~g}$ of 2-mercaptoethanesulfonate (sodium salt; $7.0 \mathrm{mmol}$ ) in $23 \mathrm{~mL}$ of $0.335 \mathrm{M}$ sodium methanolate $(6.09 \mathrm{mmol})$ at $0{ }^{\circ} \mathrm{C}$ (ice bath) and stirred at room temperature for $14 \mathrm{~h}$. The dried residue was dissolved in a small amount of water, acidified with Amberlite IR-120 to $\mathrm{pH} 1$, treated with concentrated $\mathrm{NH}_{3}$ (aq) to give $\mathrm{pH} \mathrm{12}$, and lyophilized to give $1.10 \mathrm{~g}$ of pure $\left(>99 \%{ }^{13} \mathrm{C}\right.$-labeled according to ${ }^{1} \mathrm{H}$ NMR) 2 (6.31 mmol; 90\%). ${ }^{1} \mathrm{H}$ NMR $\left(\mathrm{D}_{2} \mathrm{O}, 400 \mathrm{MHz}\right) \delta 1.98-2.32$ 
(d, $J=139.4,3 \mathrm{H}), 2.83-2.88(\mathrm{~m}, 2 \mathrm{H}), 3.15-3.19$ (m, 2H).

${ }^{13} \mathrm{C}$ NMR $\left(\mathrm{D}_{2} \mathrm{O}, 400 \mathrm{MHz}\right) \delta 17.00$ (100), $30.36(1), 53.33$

(1). ESI-MS: m/z 206.1 (8), 46.4 (9), 334.8 (13), 125.1

(15), 62.3 (67), 156.0 (100).

Preparation of an EPR sample of $\mathrm{Ni}(\mathrm{I}) \mathrm{F}_{430}$ pentamethyl ester in tetrahydrofuran/2-methyl-tetrahydrofuran

$\mathrm{Ni}(\mathrm{II}) \mathrm{F}_{430}$ pentamethyl ester $\left(\mathrm{ClO}_{4}{ }^{-}\right.$salt $)\left[\mathrm{F}_{430 \mathrm{M}}\right]$ was prepared via exhaustive methylation of crude $\mathrm{Ni}(\mathrm{II}) \mathrm{F}_{430}$ pentacarboxylic acid in methanol $/ p$ - TsOH and purified by thin-layer chromatography as described [29]. To achieve the removal of all of the methylene chloride remaining from the isolation procedure, the pentamethyl ester was dissolved in THF/toluene 1:1 (v/v) and the solvent mixture was evaporated three times. A solution of $0.5 \mu \mathrm{mol} \mathrm{F}_{430 \mathrm{M}}$ in $400 \mu \mathrm{L} \mathrm{THF/2-methyl-THF} \mathrm{2:8} \mathrm{(v/v)} \mathrm{was} \mathrm{placed} \mathrm{in} \mathrm{one}$ side arm of a glass apparatus with two side arms as well as a sealed-on UV/VIS cell $(d=0.024 \mathrm{~cm})$ and an X-band quartz EPR tube. Both organic solvents were freshly distilled from metallic potassium. Two hundred microliters of liquid $0.025 \%(\mathrm{w} / \mathrm{w}) \mathrm{Na}-\mathrm{Hg}$ were placed in the other side arm, which was separated from the main compartment by a fritted glass disk (porosity P3). Both the $\mathrm{F}_{430 \mathrm{M}}$ solution and the amalgam were degassed by performing three freezethaw cycles at $10^{-5}$ mbar, and the whole apparatus was sealed under high vacuum. Quantitative reduction of $\mathrm{Ni}(\mathrm{II}) \mathrm{F}_{430 \mathrm{M}}$ to the $\mathrm{Ni}(\mathrm{I})$ form was brought about by controlled contact with the amalgam while following the progress by UV/VIS spectroscopy. The final solution of $\mathrm{Ni}(\mathrm{I}) \mathrm{F}_{430 \mathrm{M}}$ was then allowed to flow into the EPR tube, which was sealed off under vacuum after freezing the solution at $77 \mathrm{~K}$ to form a glass.

\section{EPR spectroscopy [30]}

The Q-band (35 GHz) experiments were carried out on an instrument built in-house [31] and equipped with a helium gas-flow cryostat from Oxford Instruments, Inc. (Beckenham, UK). All X- and W-band $(9.7 / 94 \mathrm{GHz})$ measurements were carried out on a Bruker (Karlsruhe, Germany) E680 spectrometer. The ${ }^{13} \mathrm{C}$ X-band Davies ENDOR [30, 32] spectra were measured at $25 \mathrm{~K}$ with the mw pulse sequence $\pi-T-\pi / 2-\tau-\pi-\tau-$ echo, with mw pulses of length $t_{\pi / 2}=400 \mathrm{~ns}$ and $t_{\pi}=800 \mathrm{~ns}, \tau=1,600 \mathrm{~ns}$, and a radiofrequency pulse of length $28.5 \mu$ s and with variable frequency $v_{\text {rf }}$ applied for a time $T=30 \mu \mathrm{s}$. A low-pass filter with a cut-off frequency of $7 \mathrm{MHz}$ was used to avoid artifacts from higher-rf harmonics. The W-band MIMS ${ }^{13} \mathrm{C}$ ENDOR spectra were measured at $15 \mathrm{~K}$ with the mw pulse sequence $\pi / 2-\tau-\pi / 2-T-\pi / 2-\tau-$ echo, with $\mathrm{mw}$ pulses of length $t_{\pi / 2}=24 \mathrm{~ns}, \tau=300-500 \mathrm{~ns}$ as indicated, and a radiofrequency pulse of length $48 \mu$ s and with variable frequency $v_{\mathrm{rf}}$ applied for a time $T=50 \mu$ s. The variable mixing time W-band MIMS ENDOR experiments [33, 34] (see Figure $\mathrm{S} 1$ in the Supplementary material) with the mw sequence $\pi / 2-\tau-\pi / 2-T-t_{\text {mix }}-\pi / 2-\tau-$ echo were performed at $10 \mathrm{~K}$ with a repetition time of $20 \mathrm{~ms}$ and with mixing times $t_{\text {mix }}=0 \mathrm{~ms}, 1.5 \mathrm{~ms}$ (all other parameters were the same as for the W-band MIMS ENDOR measurements). The asymmetry of the ENDOR peaks as the time $t_{\text {mix }}$ is increased can then be used to determine the absolute sign of the hyperfine interaction.

HYSCORE (hyperfine sublevel correlation spectroscopy) [35] is a two-dimensional (2D) experiment which correlates nuclear frequencies in one electron spin manifold with nuclear frequencies in the other electron spin manifold. X-band $(9.7 \mathrm{GHz})$ HYSCORE spectra were measured at $25 \mathrm{~K}$ with a repetition time of $1.5 \mathrm{~ms}$ using the sequence $\pi / 2-\tau-\pi / 2-t_{1}-\pi-t_{2}-\pi / 2-\tau-$ echo. The $\mathrm{mw}$ pulse lengths were $t_{\pi / 2}=20 \mathrm{~ns}$ and $t_{\pi}=16 \mathrm{~ns}$, starting times $t_{10}=t_{20}=96 \mathrm{~ns}$, and a time increment of $\Delta t=20 \mathrm{~ns}$ (data matrix $350 \times 350$ ) was used. Q-band Matched-HYSCORE spectra [36, 37] were measured with a loop gap resonator [38] at $30 \mathrm{~K}$ using a repetition time of $1 \mathrm{~ms}$ and the sequence $\pi / 2-\tau-t_{\mathrm{m}}-t_{1}-\pi-t_{2}-t_{\mathrm{m}}-\tau$-echo. The mw pulse lengths were $t_{\pi}=t_{\pi / 2}=16 \mathrm{~ns}$, with matched pulses of length $t_{\mathrm{m}}=46 \mathrm{~ns}$ (mw field strength $\omega_{1} / 2 \pi=83.3 \mathrm{MHz}$ ), starting times for $t_{1}$ and $t_{2}$ of $96 \mathrm{ns,}$ a time increment of $\Delta t=12 \mathrm{~ns}$ (data matrix $256 \times 256$ ), and $\tau=108 \mathrm{~ns}$. All HYSCORE data were processed with MATLAB 7.0 (The MathWorks, Inc., Natick, MA, USA). The time traces were baseline-corrected with an exponential function, apodized with a Gaussian window, and zero-filled. After a 2D Fourier transform, absolute-value spectra were calculated. All measurements used an eightstep phase cycle to remove unwanted echoes. The fieldswept EPR and Davies ENDOR spectra were simulated with the MATLAB-based program package EasySpin [39], and the HYSCORE spectra with a program written in-house [40].

\section{Density functional theory calculations}

Structural optimizations were carried out with the Turbomole program package [41] by employing two different density functionals, namely the pure functional BP86 [42, 43] (in combination with the resolution-of-the-identity density fitting technique with Karlsruhe auxiliary basis sets [44]) and the hybrid functional B3LYP (i.e., Becke's threeparameter functional in combination with the LYP correlation functional [45, 46], as implemented in Turbomole). For all calculations, the valence-triple-zeta plus polarization basis set TZVP by Schäfer et al. [47] was applied. Coordination energies are given below for the structure optimized with the functional BP86. EPR-spectroscopic 
parameters were obtained by ADF calculations only for the BP86/TZVP structure (see Tables S1, S2, Figure S6). It is well known that BP86 structures of transition metal complexes are in general more reliable than B3LYP structures when compared to X-ray structural data. The (exothermic) coordination energy of the thioether to the nickel ion at $0 \mathrm{~K}$ amounts to $-16.9 \mathrm{~kJ} / \mathrm{mol}$. This energy has been obtained for relaxed isolated fragments, i.e., for $\mathrm{CH}_{3}-\mathrm{S}-\mathrm{CoM}$ and the metal fragment, respectively.

The hyperfine interactions were calculated with the Amsterdam Density Functional package (ADF 2005.01) [48]. The functional RPBE [49] with the relativistic scalar zeroth-order regular approximation (ZORA [50]) was employed. The calculation was spin-unrestricted, with a Slater-type basis set of triple- $\zeta$ quality with two polarization functions (TZ2P) with no frozen cores, as implemented in ADF.

\section{Results and discussion}

Figure 1 displays echo-detected W-band $(94.2587 \mathrm{GHz})$ EPR spectra of $\mathrm{MCR}_{\text {red1a }}$ (containing $\mathrm{Ni}(\mathrm{I}) \mathrm{F}_{430}$ in the "absence" of a substrate) and of $\mathrm{MCR}_{\mathrm{red} 1 \mathrm{~m}}$, the species

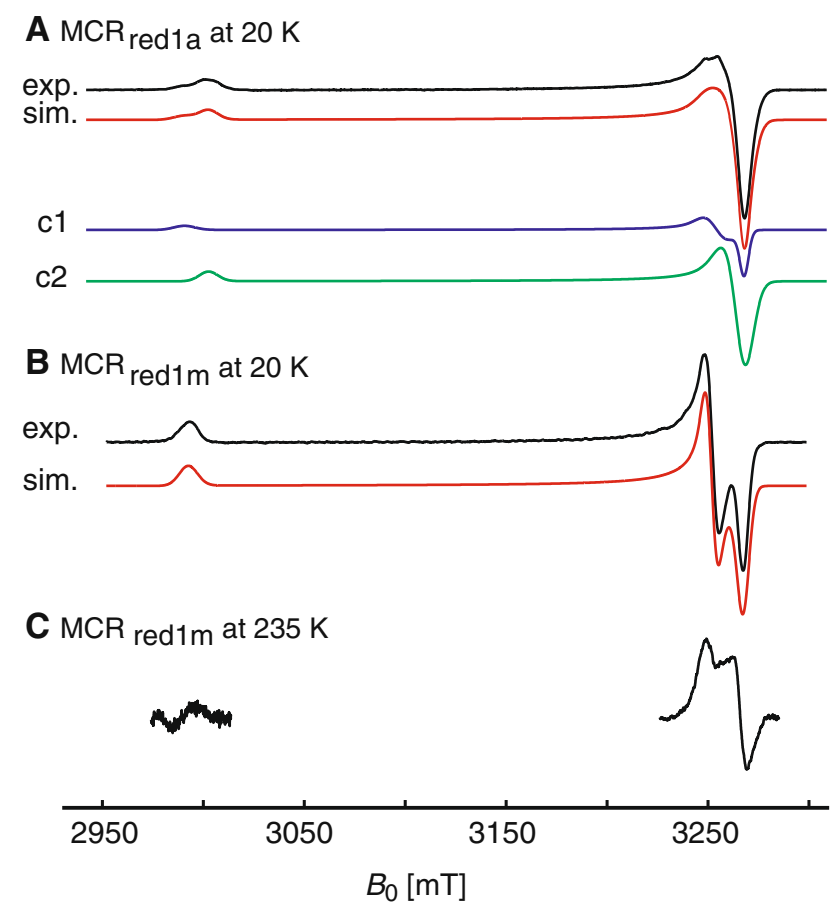

Fig. 1 W-band $(94.2587 \mathrm{GHz})$ EPR spectra of $(A) \mathrm{MCR}_{\text {red1a }}$ and $(B, C) \mathrm{MCR}_{\mathrm{red} 1 \mathrm{~m}} . A$ and $B$ show the echo-detected field-swept EPR spectrum measured at $20 \mathrm{~K}$. The numerically calculated first derivative is shown in each case. $C$ shows the CW EPR spectrum recorded at $235 \mathrm{~K}$. The $\mathrm{MCR}_{\text {red1a }}$ sample was simulated by two components, c1 (assigned to $\mathrm{MCR}_{\mathrm{red} 1 \mathrm{c}}$ ) and $c 2$ (assigned to $\mathrm{MCR}_{\mathrm{red} 1 \mathrm{a}}$ ), and $\mathrm{MCR}_{\text {red } 1 \mathrm{~m}}$ was simulated by a single component with a rhombic $g$-matrix
Table 1 Principal $g$ values and linewidths $L$ for $\mathrm{MCR}_{\text {redla }}$, $\mathrm{MCR}_{\text {red1m }}$, and $\mathrm{MCR}_{\text {red1c }}$

\begin{tabular}{llll}
\hline Complex & Percentage $(\%)$ & $g_{1}, g_{2}, g_{3}$ & $L_{1}, L_{2}, L_{3}(\mathrm{MHz})$ \\
\hline red1a & $\mathrm{c} 1: 33^{\mathrm{a}}$ & $2.061,2.070,2.252$ & $140,340,390$ \\
& $\mathrm{c} 2: 67^{\mathrm{b}}$ & $2.061,2.064,2.243$ & $280,400,340$ \\
red1m & - & $2.061,2.071,2.251$ & $200,180,330$ \\
red1c & - & $2.063,2.068,2.248$ & $180,300,300$ \\
\hline
\end{tabular}

a Assigned to $\mathrm{MCR}_{\text {red1c }}$ due to the presence of the impurity HS-CoM

b Assigned to $\mathrm{MCR}_{\text {red1a }}$

formed when $\mathrm{CH}_{3}-\mathrm{S}-\mathrm{CoM}$ is added to a $\mathrm{MCR}_{\text {red1a }}$ preparation. $\mathrm{MCR}_{\text {red1a }}$ displays an EPR spectrum that can be simulated by two species labeled c1 $(33 \%)$ and $\mathrm{c} 2$ $(67 \%) . \quad \mathrm{c} 1$ is most likely the species $\mathrm{MCR}_{\text {red1c }}$ $\left(\mathrm{MCR}_{\mathrm{red} 1 \mathrm{a}} \underset{-\mathrm{H}-\mathrm{SCOM}}{\stackrel{+\mathrm{H}-\mathrm{SCoM}}{\rightleftarrows}} \mathrm{MCR}_{\text {redlc }}\right.$, with "c" denoting the presence of coenzyme $\mathrm{M}$ ), since $\mathrm{c} 1$ has similar $\mathrm{g}$ values to those of a $\mathrm{MCR}_{\text {red1c }}$ preparation (see the bottom row of Table 1) and HS-CoM is known to be present in the preparations in small quantities and to be difficult to remove completely. Species c2 is thus assigned to the "true" $\mathrm{MCR}_{\text {red1a }}$ complex without a bound substrate and has an axial EPR spectrum $\left(g_{1} \approx g_{2} \neq g_{3}\right)$. The addition of the substrate $\mathrm{CH}_{3}-\mathrm{S}-\mathrm{CoM}$ causes a small but clearly discernable change in the EPR spectrum, with a well-resolved rhombic splitting $\left(g_{1} \neq g_{2} \neq g_{3}\right)$, and the spectrum can be simulated by a single species with a rhombic $g$-matrix.

The induction of rhombicity in the $g$-matrix upon the addition of substrates has also been observed when HS$\mathrm{CoM}$ is added to $\mathrm{MCR}_{\text {red1a }}$ to form $\mathrm{MCR}_{\text {red1c }}$, and is an indication that a small change in the electronic structure takes place such that the electronic ground state $\left(d_{x^{2}-y^{2}}\right)$ has a larger $d_{z^{2}}$-component admixture through interaction with a proximal ligand.

A comparison between the echo-detected spectrum recorded at $20 \mathrm{~K}$ and the $\mathrm{CW}$ spectrum recorded at $235 \mathrm{~K}$ shows that the complex $\mathrm{MCR}_{\text {red1m }}$ is stable in this temperature range, and provides an indication that the complex could well be stable at the physiological temperature of the enzyme at approximately $60{ }^{\circ} \mathrm{C}$.

Hydropyrrolic nitrogens of $F_{430}$

To characterize the electronic and geometric structure of $\mathrm{MCR}_{\text {red } 1 \mathrm{~m}}$, we studied the interactions of the Ni-centered electron spin with the four hydropyrrolic nitrogens of $\mathrm{F}_{430}$. The nitrogen nuclei have large hyperfine couplings, resulting in well-resolved splittings in the X-band CW EPR spectrum, as shown in Fig. 2a. To improve the accuracy of the determined EPR parameters, a matched HYSCORE spectrum (Fig. 2b) and Q-band Davies ENDOR spectra 

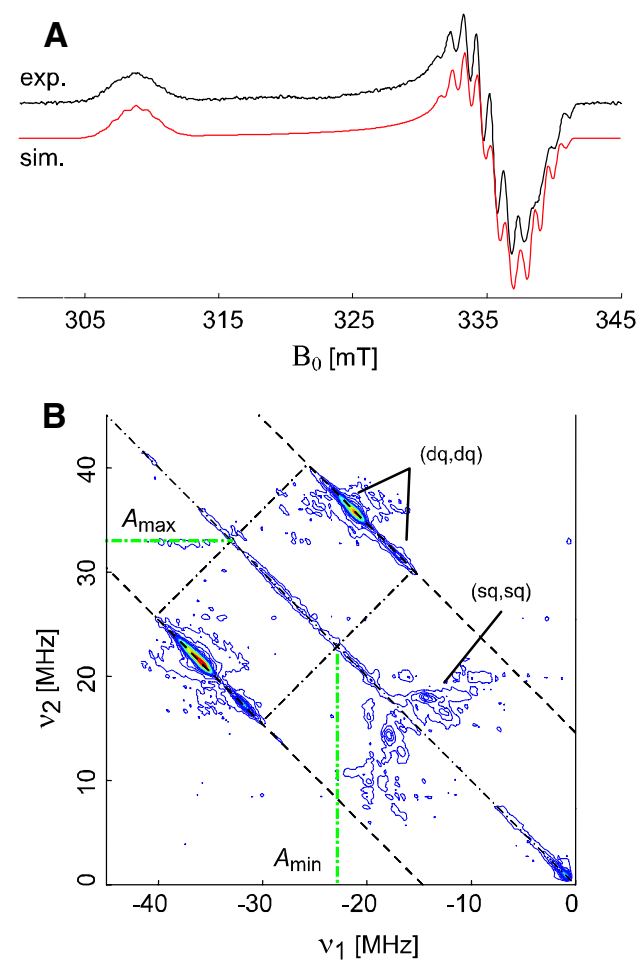

Fig. 2 a X-band CW EPR spectra of $\mathrm{MCR}_{\text {red } 1 \mathrm{~m}}$ derived from experiment (upper trace in black) and a simulation (lower trace in $r e d$ ) calculated with the principal $g$ values determined from the Wband EPR spectrum and including the four hydropyrrolic ${ }^{14} \mathrm{~N}$ hyperfine interactions. b Q-band $(34.3678 \mathrm{GHz})$ matched HYSCORE spectrum measured at the intensity maximum of the EPR spectrum showing nitrogen double-quantum cross-peaks which indicate hyperfine couplings in the range from 23 to $33 \mathrm{MHz}$. c Q-band

(Fig. 2c) were also recorded. The matched HYSCORE spectrum was used to supplement the data recorded at the observer positions representing $g_{1} / g_{2}$ (close to the CW EPR spectral maximum), where the signals are most complicated due to many contributing orientations. In this spectrum, the positions of the double-quantum cross-peaks, which are, to first order, free from the nuclear quadrupole interaction (NQI) and are centered at the hyperfine coupling $A$ and split by $4 v_{\mathrm{I}}\left(v_{\mathrm{I}}\right.$ is the nuclear Larmor frequency), show that the hyperfine couplings $A_{1} / A_{2}$ range from $23-33 \mathrm{MHz}$. The ${ }^{14} \mathrm{~N}$ signals in the $\mathrm{CW}$ EPR and Q-band ENDOR spectra were then simulated with this constraint to give the best fit to the data, which resulted in the hyperfine and nuclear quadrupole parameters given in Table 2. To reduce the number of fitted parameters, the Euler angles were fixed in line with single-crystal metalloporphyrin studies [51] where the axis of the largest principal hyperfine and nuclear quadrupole value point at the nickel ion [52]. Given the large number of adjustable parameters (five coupling parameters for each nitrogen), the error in the parameters is comparable to the relatively small difference between the nitrogen couplings, in

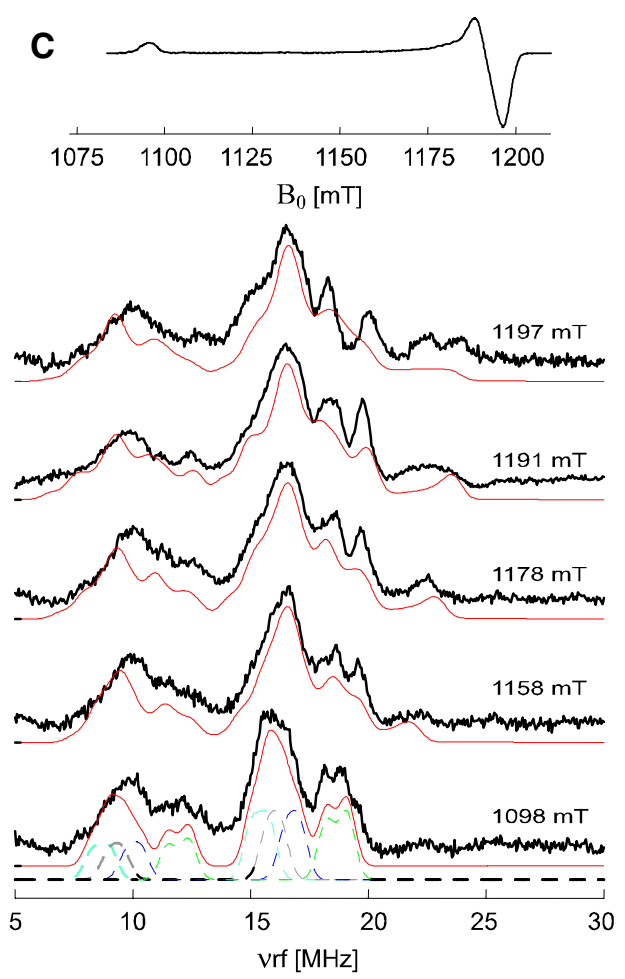

(34.5038 GHz) spectra. The field-swept EPR spectrum $(20 \mathrm{~K})$ is shown at the top; below this are Davies ENDOR spectra measured at $20 \mathrm{~K}$ at the observer positions indicated. The upper traces show the experimental spectra; the simulations consisting of the sum of signals from the four hydropyrrolic nitrogens are slightly shifted downwards from these. For the field position of $1,098 \mathrm{mT}$, the four nitrogen components are shown as dashed lines

particular in the $\mathbf{g}_{1}-\mathbf{g}_{2}$ plane. At the "single-crystal" observer position corresponding to $g_{3}$ (Fig. 2c, 1,098 mT), however, the resolution is significantly better and the simulation shows that there are three nitrogens with similar couplings $[|A|=(24.0-26.8) \mathrm{MHz}]$, and one with a slightly larger coupling $[|A|=30.4 \mathrm{MHz}]$. The optimized values are comparable with those given for the species $\mathrm{MCR}_{\text {red1c }}$ [53], $\mathrm{MCR}_{\mathrm{BPS}}[14,15]$, and $\mathrm{MCR}_{\mathrm{ox} 1}$ [54], but vastly different from those of $\mathrm{MCR}_{\text {red2r }}$ [53], where the four $\mathrm{F}_{430}$ hydropyrrolic nitrogen hyperfine interactions span a large range, indicating a significant asymmetry in the spin-density distribution (this species has a strong proximal sulfur ligand from HS-CoM). The outcome for $\mathrm{MCR}_{\text {red } 1 \mathrm{~m}}$ is that the spin-density distribution on $F_{430}$ is not significantly perturbed by the weak axial ligand.

\section{Addition of isotope-labeled $\left({ }^{13} \mathrm{C} /{ }^{1} \mathrm{H} /{ }^{2} \mathrm{H}\right) \mathrm{CH}_{3}$-CoM}

Using selectively isotope-labeled $\mathrm{CH}_{3}-\mathrm{S}-\mathrm{CoM}$, we have studied the hyperfine (and nuclear quadrupole) interactions of the substrate added to $\mathrm{Ni}(\mathrm{I}) \mathrm{F}_{430}$ when the $\mathrm{MCR}_{\text {red1m }}$ state is formed. 
Table 2 Measured $\mathrm{MCR}_{\text {red1m }}$ hyperfine and nuclear quadrupole parameters

\begin{tabular}{|c|c|c|c|c|c|c|c|c|}
\hline Nucleus & Description & $A_{1}(\mathrm{MHz})$ & $A_{2}(\mathrm{MHz})$ & $A_{3}(\mathrm{MHz})$ & {$[\alpha, \beta, \gamma]^{\mathrm{a}}\left({ }^{\circ}\right)$} & $\left|e^{2} q Q / h\right|^{\mathrm{b}}(\mathrm{MHz})$ & $\eta^{\mathrm{b}}$ & $\overline{[\alpha, \beta, \gamma]^{\mathrm{a}}\left({ }^{\circ}\right)}$ \\
\hline \multirow[t]{4}{*}{${ }^{14} \mathrm{~N}$} & \multirow{4}{*}{$\begin{array}{l}\text { Hydropyrrolic } \\
\text { nitrogens of } F_{430}\end{array}$} & $25.4^{\mathrm{c}}$ & $26.8^{\mathrm{c}}$ & $24.0^{\mathrm{c}}$ & $45,0,0$ & 1.2 & 0.1 & $45,90,0$ \\
\hline & & 23.3 & 26.3 & 25.2 & $135,0,0$ & 2.7 & 0.7 & $135,90,0$ \\
\hline & & 24.7 & 29.2 & 26.8 & $225,0,0$ & 2.4 & 0.6 & $225,90,0$ \\
\hline & & 28.2 & 34.4 & 30.4 & $315,0,0$ & 3.9 & 0.7 & $315,90,0$ \\
\hline${ }^{14} \mathrm{~N}$ & $\operatorname{Gln}^{\alpha^{\prime} 147}$ & $0.5 \pm 0.1$ & & $0.6 \pm 0.1$ & $-, 20,-$ & 2.6 & 0.2 & $80,100,0$ \\
\hline \multirow[t]{2}{*}{${ }^{13} \mathrm{C}$ methyl } & \multirow[t]{2}{*}{${ }^{13} \mathrm{CH}_{3}-\mathrm{S}-\mathrm{CoM}$} & $-1.3 \pm 0.1^{\mathrm{d}}$ & & $-0.8 \pm 0.1$ & $-, 30,130$ & - & - & - \\
\hline & & $0.0-0.5$ & & & - & - & - & - \\
\hline${ }^{1} \mathrm{H}^{\text {maximum }}$ methyl & $\mathrm{CH}_{3}$-S-CoM & $-0.55 \pm 0.1$ & & $1.1 \pm 0.1$ & $-, 0,-$ & - & - & - \\
\hline
\end{tabular}

a Euler angles define the rotation of the hyperfine or nuclear quadrupole principal axis system into the $g$-matrix principal axis system, e.g., $\mathbf{A}=\mathbf{R}(\alpha, \beta, \gamma) \mathbf{A}_{\text {diagonal }} \mathbf{R}^{\dagger}(\alpha, \beta, \gamma)$

${ }^{\mathrm{b}}$ Nuclear quadrupole interactions $\kappa=e^{2} q Q /(h 4 I(2 I-1))$ and asymmetry parameters $\eta=\left(Q_{x}-Q_{y}\right) / Q_{z} \quad$ with $\quad Q_{x}=-\kappa(1-\eta)$, $Q_{y}=-\kappa(1+\eta)$, and $Q_{z}=2 \kappa$

c Errors in each hyperfine principal value are estimated to be $\pm 1 \mathrm{MHz}$

${ }^{d}$ Relative population $>90 \%$ with an ENDOR linewidth of $0.2 \mathrm{MHz}$

\section{${ }^{13} \mathrm{CH}_{3}-\mathrm{S}-\mathrm{CoM}$}

Carbon signals from ${ }^{13} \mathrm{CH}_{3}-\mathrm{S}-\mathrm{CoM}$ could be observed at X-band with Davies ENDOR (Fig. 3a) using a very selective inversion $\pi \mathrm{mw}$ pulse of length $800 \mathrm{~ns}$, or at $\mathrm{W}$-band using Mims ENDOR (Fig. 3c) with a long $\tau$ value of 300500 ns. Data at both mw frequencies show a major component with ${ }^{13} \mathrm{C}$ signals in the range $\pm(0.3-0.8) \mathrm{MHz}$, and much weaker signals in the range $\pm(0-0.5) \mathrm{MHz}$ from a minor component. This can be best appreciated by inspecting Fig. 3b, which was measured with a long $\tau$ value (500 ns) to enhance the smaller splittings. The figure displays a main peak at ca. $\pm 0.6 \mathrm{MHz}$, and a weaker one marked by diamonds at ca. $\pm 0.2 \mathrm{MHz}$; the control experiment using unlabeled $\mathrm{CH}_{3}-\mathrm{S}-\mathrm{CoM}$ showed no detectable carbon signals (green trace in Fig. 3b). A variable mixing time ENDOR experiment [33, 34] (see Fig. S1) performed at $10 \mathrm{~K}$ shows that the hyperfine interaction from the major component is negative. Note that the sign and the strength of the ${ }^{13} \mathrm{C}$ hyperfine coupling is much smaller than those observed in compounds that feature a direct $\mathrm{Ni}$-alkyl bond such as $\mathrm{MCR}_{\mathrm{BPS}}$ prepared from ${ }^{13} \mathrm{C}$-enriched 3-bromopropane sulfonate, $\mathrm{MCR}_{\mathrm{BrMe}}$ (prepared from methyl bromide), and $\mathrm{MCR}_{\mathrm{IMe}}$ (prepared from methyl iodide; note that $\mathrm{MCR}_{\mathrm{BrMe}}$ and $\mathrm{MCR}_{\mathrm{IMe}}$ denote the same species and are only named differently based on their preparation) [14-17].

A model containing two carbons with axial hyperfine interactions was investigated and found to give a satisfactory fit to the data (Table 2). Component 1: $>90 \%$, $A^{1}=-[1.3,1.3,0.8] \mathrm{MHz}=-1.1+[-0.16,-0.16$, $0.33] \mathrm{MHz}$, linewidth $0.2 \mathrm{MHz}$; component 2: not well defined but has couplings in the range $\left|A^{2}\right|=(0.0-$ $0.5) \mathrm{MHz}$. The relatively large ENDOR linewidth of the major component $\left(A^{1}\right)$ indicates a distribution of hyperfine interactions and thus that the methyl group has a certain degree of structural freedom. The hyperfine coupling $A^{1}$ has an isotropic part $a_{\text {iso }}{ }^{1}=-1.1 \mathrm{MHz}$ which indicates that there is a Fermi contact interaction $a_{\text {iso }}=$ $\frac{2 \mu_{0}}{3 \hbar} g_{e} \beta_{e} g_{n} \beta_{n}\left|\psi_{0}(0)\right|^{2}$, and thus that $\mathrm{CH}_{3}-\mathrm{S}-\mathrm{CoM}$ is coordinated to $\mathrm{Ni}^{\mathrm{I}} \mathrm{F}_{430}$. Note that the contribution of the pseudo-isotropic interaction

$\mathbf{A}^{L}=\Delta \mathbf{g T} / g_{e}=a_{\text {iso }}^{L}+\mathbf{A}_{\text {aniso }}^{L}$

is far too small to explain the observed $a_{\text {iso }}$ value [30]. Using $\left[\Delta g_{1} \Delta g_{2} \Delta g_{2}\right]=[0.249,0.069,0.059]$ and the ${ }^{13} \mathrm{C}$ principal values to give the dipolar part $\left[T_{1}, T_{2}\right.$, $\left.T_{3}\right]=[-0.16,-0.16,0.33] \mathrm{MHz}$ gives an upper limit of $\left|a_{\text {iso }}^{\mathrm{F}}\right|<0.02 \mathrm{MHz}$. This value is far too small to explain the experimental value.

The ${ }^{13} \mathrm{C}$ hyperfine interactions indicate that $\mathrm{CH}_{3}-\mathrm{S}-\mathrm{CoM}$ can coordinate to $\mathrm{F}_{430}$ in most probably two different configurations with large degrees of freedom. The structural freedom leads to a relatively broad distribution in the couplings and thus broad ENDOR lines, modeled by a large linewidth. The structural freedom of the major component $(>90 \%)$ may be the angle of the methyl group around the $\mathrm{S}-\mathrm{C}_{\beta}$ bond relative to $\mathrm{F}_{430}$ (i.e., the $\mathrm{CH}_{3}$ group pointing into and out of the plane of the paper in Structure 1$)$. The minor component $(<10 \%)$ could be due to a small percentage of $\mathrm{CH}_{3}-\mathrm{S}-\mathrm{CoM}$ that is close to but not chemically bound to the nickel ion.

\section{$\mathrm{CH}_{3}-\mathrm{S}-\mathrm{CoM}$ and $\mathrm{CD}_{3}-\mathrm{S}-\mathrm{CoM}$}

Deuterium signals from the methyl nuclei can be unambiguously identified with X-band HYSCORE with the substrate $\mathrm{CD}_{3}$-S-CoM, or with Q-band ENDOR by comparing the signals from samples with those from the substrates 


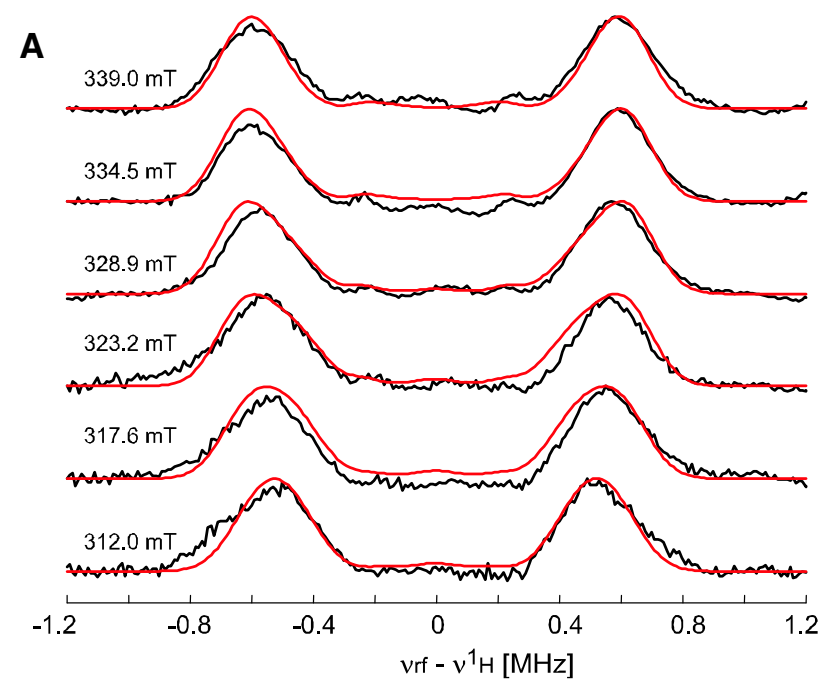

B $12 \mathrm{C}$
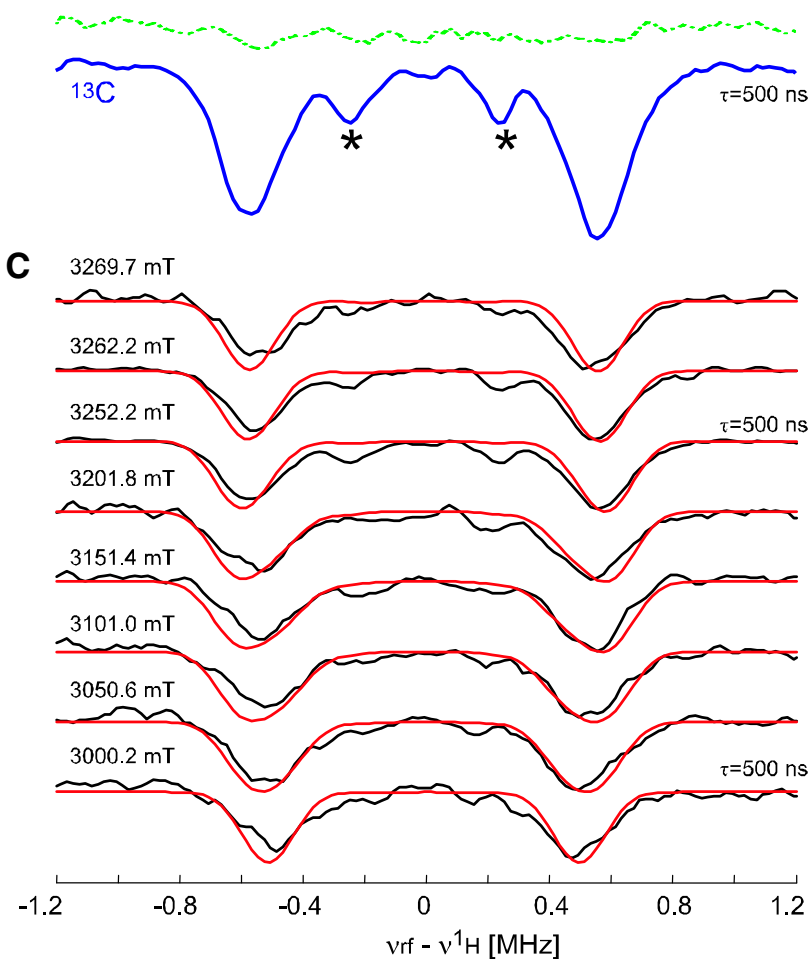

Fig. $3{ }^{13} \mathrm{C}$ ENDOR spectra from $\mathrm{MCR}_{\text {red } 1 \mathrm{~m}}$ with ${ }^{13} \mathrm{CH}_{3}$-S-CoM. a X-band $(9.7249 \mathrm{GHz})$ Davies ENDOR spectra measured at $25 \mathrm{~K}$ at the observer positions indicated. The inversion $\pi$ pulse in the mw sequence was $800 \mathrm{~ns}$ long (excitation width, fwhh $\sim 0.7 \mathrm{MHz}$ ); simulations are shown as red lines. b, $\mathbf{c}$ W-band $(94.274 \mathrm{GHz}) \mathrm{Mims}$ ENDOR spectra measured at $15 \mathrm{~K}$ with a $\tau$ of 300 ns unless indicated otherwise at the observer positions indicated. $\mathbf{b}$ is recorded at the observer position of the intensity maximum of the field-swept EPR spectrum and shows a trace from a ${ }^{12} \mathrm{CH}_{3}-\mathrm{S}-\mathrm{CoM}$ (green) and a ${ }^{13} \mathrm{CH}_{3}$-S-CoM (blue) $\mathrm{MCR}_{\text {red1m }}$ sample. Asterisks highlight methyl ${ }^{13} \mathrm{C}$ signals which imply that a second distinct configuration of $\mathrm{MCR}_{\mathrm{red} 1 \mathrm{~m}}$ exists. In $\mathbf{c}$, the red lines are the simulations for the methyl ${ }^{13} \mathrm{C}$ nucleus, corrected for the $\tau$-dependent blind spots by $I\left(v_{\mathrm{rf}}\right)=I$ $\sin \left(2 \pi\left(v_{\mathrm{rf}}-v_{1 \mathrm{H}}\right) \tau\right)^{2}$

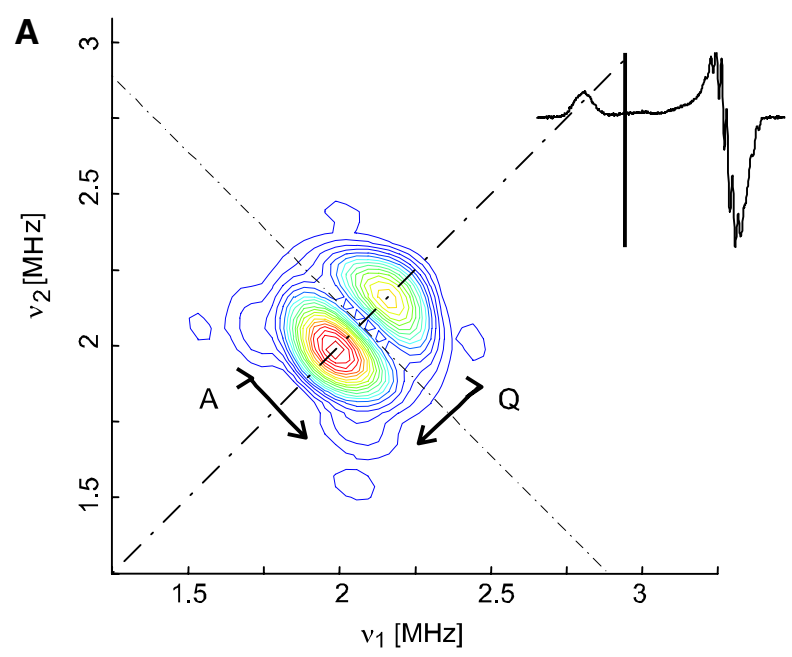

B
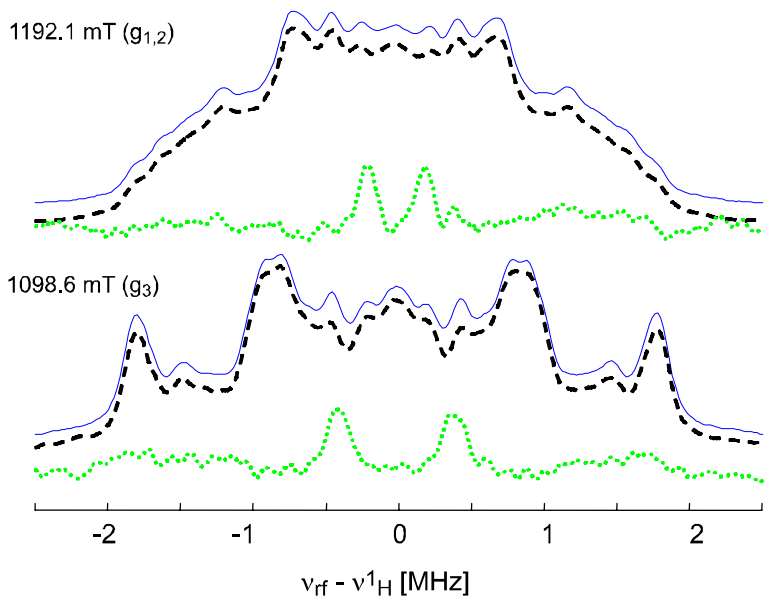

Fig. 4 Methyl signals from $\mathrm{CD}_{3}-\mathrm{S}-\mathrm{CoM} / \mathrm{CH}_{3}-\mathrm{S}-\mathrm{CoM}$ in $\mathrm{MCR}_{\mathrm{red} 1 \mathrm{~m}}$. a ${ }^{2} \mathrm{H}$ X-band $(9.73 \mathrm{GHz}) \mathrm{HYSCORE}$ spectrum of the $\mathrm{CD}_{3}-\mathrm{S}-\mathrm{CoM}$ sample measured at $12.5 \mathrm{~K}$ at the observer position near to the field value corresponding to $g_{3}$ (low-field edge) of the field-swept EPR spectrum (see inset). b ${ }^{1} \mathrm{H}$ Q-band $(34.515 \mathrm{GHz})$ Davies ENDOR spectra measured at $25 \mathrm{~K}$ at the observer positions of the intensity maximum (near $g_{1} / g_{2}$ ) and at the low-field position (near $g_{3}$ ) of the field-swept EPR spectrum. The proton frequency regions from the $\mathrm{CH}_{3}$-S-CoM sample (solid blue line), the $\mathrm{CD}_{3}-\mathrm{S}-\mathrm{CoM}$ sample (dashed black line), and the difference between those two (dotted green line, not to scale), which highlights signals from the methyl protons of methyl-coenzyme M, are shown

$\mathrm{CH}_{3}$-S-CoM and $\mathrm{CD}_{3}$-S-CoM. Figure $4 \mathrm{a}$ shows the lowfrequency region of a HYSCORE spectrum measured at $\mathrm{X}$-band, where a clear deuterium signal that is split by the nuclear quadrupole interaction is observed. The full set of HYSCORE spectra measured at five field positions is shown in Fig. S2. Simulations of these data show that the methyl proton hyperfine interactions are in the range $\left|A\left({ }^{1} \mathrm{H}\right)\right|=$ $(-0.5,-0.5,+1.0) \mathrm{MHz}\left[A\left({ }^{1} \mathrm{H}\right)=A\left({ }^{2} \mathrm{H}\right) \times 6.5144\right]$.

This small deuterium hyperfine coupling determined by HYSCORE is consistent with the ${ }^{1} \mathrm{H}$ Davies ENDOR data 
(Q-band, 34.515 GHz, $25 \mathrm{~K}$ ) shown in Fig. 4b for observer positions corresponding to $g_{3}$ (low-field end) and $g_{1} / g_{2}$ (intensity maximum of the EPR spectrum). The spectra from the $\mathrm{CH}_{3}-\mathrm{S}$-CoM sample (solid blue line) and the $\mathrm{CD}_{3}$ $\mathrm{S}$-CoM sample (dashed black line) are shown at both field positions. The difference spectrum (dotted green line), which highlights signals from the methyl ${ }^{1} \mathrm{H}$ nuclei, is also displayed. At the observer position corresponding to $g_{1} / g_{2}$, $\left|A\left({ }^{1} \mathrm{H}\right)\right| \approx 0.4 \mathrm{MHz}$, and at $g_{3},\left|A\left({ }^{1} \mathrm{H}\right)\right| \approx 0.8 \mathrm{MHz}$.

An estimate of the nickel-methyl proton (electronproton) distance can be obtained using the point-dipole model [55]

$\mathbf{T}=\sum_{k} \mathbf{R}_{k}(\alpha, \beta, \gamma) T_{k} \operatorname{diag}(-1,-1,2) \mathbf{R}_{k}^{\dagger}(\alpha, \beta, \gamma)$

with

$T_{k}=\left(\mu_{o} / 4 \pi h\right)\left(g_{e} \beta_{e} g_{n} \beta_{n}\right) \rho_{k} \frac{1}{r_{k}^{3}}$,

where $r_{k}$ is the distance between the unpaired electron and the $k$ th nucleus with spin population $\rho_{k}$, and $\mathbf{R}(\alpha, \beta, \gamma)$ is the rotation matrix transforming the $k$ th point-dipole interaction into the $g$-matrix principal axis system. The following spin populations were assumed: $\mathrm{Ni} 88 \%$, each hydropyrrolic nitrogen $3 \%$ (this was estimated from the corresponding hyperfine couplings). If we assume that the methyl nuclei have $a_{\text {iso }}\left({ }^{1} \mathrm{H}\right) \approx 0$, then a lower limit for the shortest Ni$\mathrm{H}_{\text {methyl }}$ distance of $r\left(\mathrm{Ni}-\mathrm{H}_{\text {methyl }}\right)>0.5 \mathrm{~nm}$ is obtained from Eqs. 3a and $3 \mathrm{~b}$ with $T=0.6 \mathrm{MHz}\left(A\left({ }^{1} \mathrm{H}\right) \approx[-0.6,-0.6\right.$, 1.2] $\mathrm{MHz}$ ). The nickel-methyl-carbon distance cannot be accurately estimated using just the point-dipole model without knowing the hyperfine anisotropy due to carbon $p$-orbital contributions (see the DFT data later). For a ${ }^{13} \mathrm{C}$ distance of $r\left(\mathrm{Ni}-\mathrm{C}_{\text {methyl }}\right)>0.5 \mathrm{~nm}$, Eq. 2 predicts a small coupling of $T<0.16 \mathrm{MHz}$, in the range of the experimental coupling. These data imply that the methyl group points away from the nickel, as depicted in Structure 1. This methyl group orientation puts the largest principal axis of the hyperfine interaction (HI) of each methyl proton close to the orientation of the $g_{3}$ axis, consistent with the experimental data, which exhibit the largest splitting approximately along the $g_{3}$ direction. Note that, given the limited resolution of these ${ }^{1} \mathrm{H} /{ }^{2} \mathrm{H}$ data, it is not possible to determine whether one or more sets of methyl couplings contribute to the signals, as was the case for the ${ }^{13} \mathrm{C}$ methyl data.

Glutamine and lactam ${ }^{14} \mathrm{~N}$ signals

Figure 5 shows X-band $(9.7263 \mathrm{GHz})$ HYSCORE spectra recorded at the echo maximum of the field-swept EPR spectrum for (A) $\mathrm{MCR}_{\text {red1a }}$, (B) $\mathrm{MCR}_{\text {red1m, }}$, and for comparison $(\mathrm{C})$ free factor $\mathrm{Ni}(\mathrm{I}) \mathrm{F}_{430 \mathrm{M}}$ [9] in THF/2-MeTHF 1:1. The intense cross-peaks at ca. $(2.7,3.3) \mathrm{MHz}$ and (3.3, 2.7) $\mathrm{MHz}$ represent the two double-quantum (dq) signals from a weakly coupled ${ }^{14} \mathrm{~N}$ nucleus, and a comparison of the three spectra demonstrates that the weakly coupled nitrogen is very similar in $\mathrm{MCR}_{\text {red1a }}$ and $\mathrm{MCR}_{\text {red1m }}$ but nonexistent in free $F_{430 M}$. Simulation of the data (HYSCORE spectra recorded at middle- and low-field positions in the EPR spectrum are given in Fig. S3) resulted in the hyperfine coupling $\left|A\left({ }^{14} \mathrm{~N}\right)\right| \approx[0.5,0.5,0.6] \mathrm{MHz}$ and the nuclear quadrupole parameters $\mid e^{2} q Q /$ $h \mathrm{l} \approx 2.6 \mathrm{MHz}, \eta=0.2$. Since there is an isotropic contribution to the hyperfine interaction (HI), there is delocalization of the electron spin density onto this nitrogen, implying coordination of the structure to the paramagnetic center. There are two possible assignments: the $\mathrm{NH}$ nitrogen of the lactam ring of $\mathrm{F}_{430}$, or the $\mathrm{NH}_{2}$ nitrogen bound to the oxygen of $\mathrm{Gln}^{\alpha^{\prime} 147}$, which is coordinated to the nickel from the distal face in the $\mathrm{Ni}$ (II) crystal structure. The measurement of the methylated free factor $\mathrm{Ni}(\mathrm{I}) \mathrm{F}_{430 \mathrm{M}}$ can help to distinguish between the two possible assignments. Unlike MCR in the red1a or red1m states, the HYSCORE spectrum of $\mathrm{F}_{430 \mathrm{M}}$ does not show the intense nitrogen peaks; instead there is a weak peak along the diagonal (indicating $A \approx 0 \mathrm{MHz}$ ) that is assigned to the lactam nitrogen. Simulations of this feature yield $|A|<0.2 \mathrm{MHz},\left|e^{2} q Q / h\right| \approx 2.8 \mathrm{MHz}, \eta \approx 0.7$ (see also Fig. S4). The fact that the $\mathrm{F}_{430 \mathrm{M}}$ sample does not contain Gln ${ }^{\alpha^{\prime} 147}$ and that the lactam ring nitrogen signals are observed along the diagonal indicates that the intense ${ }^{14} \mathrm{~N}$ peaks in $\mathrm{MCR}_{\text {red1a }}$ and $\mathrm{MCR}_{\text {red1m }}$ should be assigned to the
Fig. 5 X-band $(9.7263 \mathrm{GHz})$ HYSCORE spectra measured at $25 \mathrm{~K}$ at the observer position of the intensity maximum of the field-swept EPR spectrum (see inset). In $\mathrm{MCR}_{\mathrm{red} 1 \mathrm{a}}(\mathbf{a})$ and $\mathrm{MCR}_{\text {redlm }}(\mathbf{b})$, the ${ }^{14} \mathrm{~N}$ peaks are assigned to the $\mathrm{NH}_{2}$ of $\mathrm{Gln}^{\alpha^{\prime} 147}$. c $\mathrm{F}_{430 \mathrm{M}}$ in $\mathrm{MeCN}$; the ${ }^{14} \mathrm{~N}$ peak is assigned to the lactam nitrogen
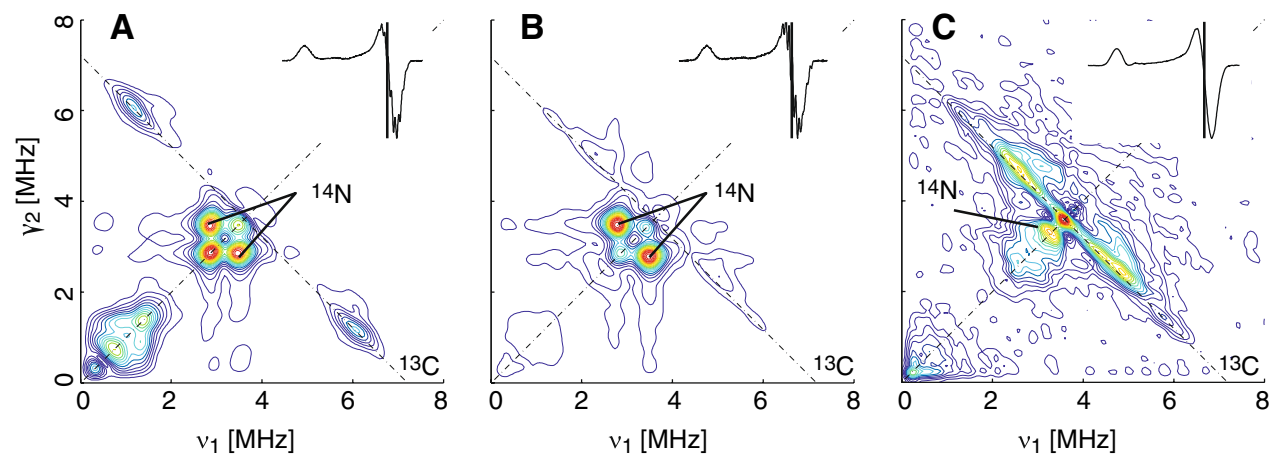
$\mathrm{NH}_{2}$ of the $\operatorname{Gln}^{\alpha^{\prime} 147}$ residue. A comparison of the NQI data with those for model compounds delivers additional indications that this assignment is the correct one [56]. Glutamine and asparagine $\mathrm{NH}_{2}$ nitrogens have $\mid e^{2} q Q /$ $h 1 \approx 2.6-2.8 \mathrm{MHz}, \eta \approx 0.3-0.4$ [57-59], whereas the $\mathrm{NH}$ nitrogens of histidine and proline have $\left|e^{2} q Q / h\right| \approx 1.4$ $1.7 \mathrm{MHz}, \eta=0.6-1.0$ [60], and the $\mathrm{NH}$ nitrogen of guanine has $\left|e^{2} q Q / \hbar\right|=2.63 \mathrm{MHz}, \eta=0.60$. Our parameters most closely resemble those of a glutamine [61]. Additionally, the $\operatorname{Gln}^{\alpha^{\prime} 147}$ residue coordinated to the nickel ion via the oxygen would be expected to have a small isotropic nitrogen HI. We thus assign this coupling to the $\mathrm{NH}_{2}$ of $\mathrm{Gln}^{\alpha^{\prime} 147}$.

\section{${ }^{1} \mathrm{H}$ signals}

The proton region of the X-band HYSCORE spectra shown in Fig. 6 allows the hyperfine interaction(s) from the proton(s) with the largest anisotropy to be estimated by making use of the frequency shift from the antidiagonal line marking the ${ }^{1} \mathrm{H}$ resonance frequency. The maximum frequency shift $\Delta v_{\max }$ behind the antidiagonal can be used to calculate the anisotropy of the hyperfine interaction,

$\Delta v_{\max }=9 T^{2} / 32 v_{1} \mathrm{H}$

where $T$ is the dipolar term of an axial hyperfine matrix with principal values $-T,-T, 2 T$. In Fig. 6 , the signal is shifted a maximum of $\Delta v_{\max }=0.25 \mathrm{MHz}$ behind the antidiagonal line, allowing an initial estimate of $T \approx 3.5 \mathrm{MHz}$. Further refinement by simulation allowed the principal values $\left|A\left({ }^{1} \mathrm{H}\right)\right| \approx[-3.2,-3.2,6.4] \mathrm{MHz}$ to be obtained, and the direction of the main axis ( $z$-axis) with respect to $\mathbf{g}_{3}$ to be estimated as $\beta \approx 35^{\circ}$. Using the pointdipolar model given in Eqs. $3 \mathrm{a}$ and $3 \mathrm{~b}$, the electron-proton distance is estimated to be approximately $0.3 \mathrm{~nm}$. The orientation of the $g_{3}$-axis and the distance are in good agreement with what is expected for either the closest $\beta$ proton of $\mathrm{CH}_{3}-\mathrm{S}-\mathrm{CoM}$ or the closest proton from the amine nitrogen $\mathrm{Gln}^{\alpha^{\prime} 147}$. In the $\mathrm{Ni}(\mathrm{II})$ crystal structure with HS-CoM and Gln ${ }^{\alpha^{\prime} 147}$ coordinated, these two protons are $0.3 \mathrm{~nm}$ from the nickel, and their nickel-proton vectors are both inclined at $\beta \approx 45^{\circ}$ to the plane of $\mathrm{F}_{430}$. In $\mathrm{MCR}_{\text {red1a }}$ (Fig. 6a), these signals are assigned to the closest proton from $\operatorname{Gln}^{\alpha^{\prime} 147}$, since there is no proximal ligand. In $\mathrm{MCR}_{\text {red1m }}$ (Fig. 6b), the observed ${ }^{1} \mathrm{H}$ signal probably has two overlapping contributions: the closest $\beta$ proton of $\mathrm{CH}_{3-}$ S-CoM and Gln ${ }^{\alpha^{\prime} 147}$.

The strength of the HI with the $\beta$ protons of methylcoenzyme $\mathrm{M}$ can be compared to the corresponding interaction with the $\beta$ proton of HS-CoM closest to the nickel in the two MCR species that have been shown to have the sulfur of CoM strongly coordinated to the nickel, namely $\mathrm{MCR}_{\mathrm{ox} 1}\left\{A\left({ }^{1} \mathrm{H}\right)=-2.0+[-3.5,-4.6,8.1] \mathrm{MHz}\right\}$ and $\mathrm{MCR}_{\text {red2r }}\left\{A\left({ }^{1} \mathrm{H}\right)=-7.8+[-3.8,-3.8,7.6] \mathrm{MHz}\right\}[54$, 62]. In all three cases, the dipolar part of the $\mathrm{HI}$ is similar, indicating similar distances of the $\beta-\mathrm{CH}_{2}$ group from the nickel. In contrast to $\mathrm{MCR}_{\mathrm{ox} 1}$ and $\mathrm{MCR}_{\mathrm{red} 2 \mathrm{r}}$, however, in $\mathrm{MCR}_{\text {red1m }}$ the isotropic part of the HI is $a_{\text {iso }} \approx 0$. This can be explained by different spin densities on the coordinated sulfur. In $\mathrm{MCR}_{\mathrm{ox} 1}$ and $\mathrm{MCR}_{\mathrm{red} 2 \mathrm{r}}$, these were estimated from the experimental ${ }^{33} \mathrm{~S}$ hyperfine coupling to be $\rho=6 \pm 3 \%$ and $\rho=7-17 \%$, respectively, resulting in a significant $a_{\text {iso }}$ on the $\beta$ protons due to spin polarization. In the case of the $\mathrm{MCR}_{\text {red } 1 \mathrm{~m}}$ presented here, the very weak coordination of the sulfur atom (and consequently the small electron spin density on the sulfur) leads to a negligibly small $a_{\text {iso }}$ on the $\beta$ protons.

\section{Coordination geometry of $\mathrm{CH}_{3}-\mathrm{S}-\mathrm{CoM}$ in $\mathrm{MCR}_{\text {red1m }}$}

From the set of measured hyperfine and nuclear quadrupole couplings, a picture of the coordination geometry of $\mathrm{CH}_{3}-\mathrm{S}-\mathrm{CoM}$ in $\mathrm{MCR}_{\text {red } 1 \mathrm{~m}}$ can be constructed. This picture is aided by density functional theory (DFT) calculations, which
Fig. 6 X-band $(9.726 \mathrm{GHz})$ HYSCORE spectra measured at $25 \mathrm{~K}$ showing the proton region. a $\mathrm{MCR}_{\text {red1a }} ; \mathbf{b} \mathrm{MCR}_{\mathrm{red} 1 \mathrm{~m}}$ $\left(\mathrm{MCR}_{\text {red1a }}+\mathrm{CH}_{3}-\mathrm{S}-\mathrm{CoM}\right)$. The observer positions correspond to $g_{3}$ (see the inset, $308.7 \mathrm{mT}$ ). Figure S5 shows supplementary Q-band ENDOR data
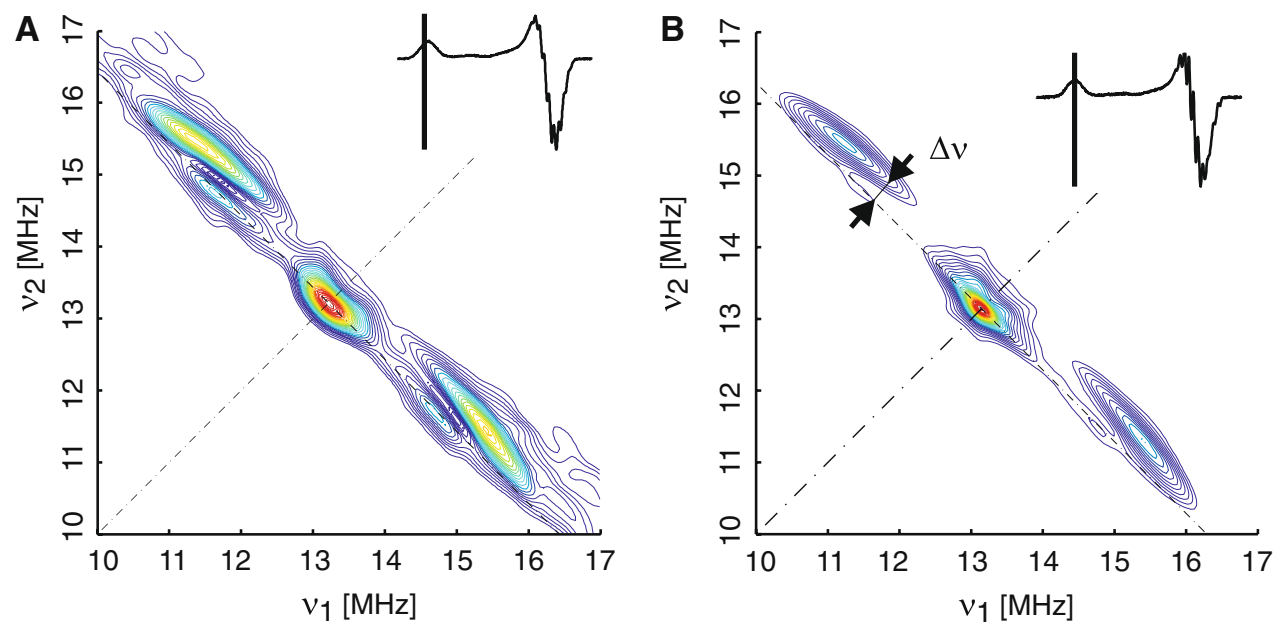


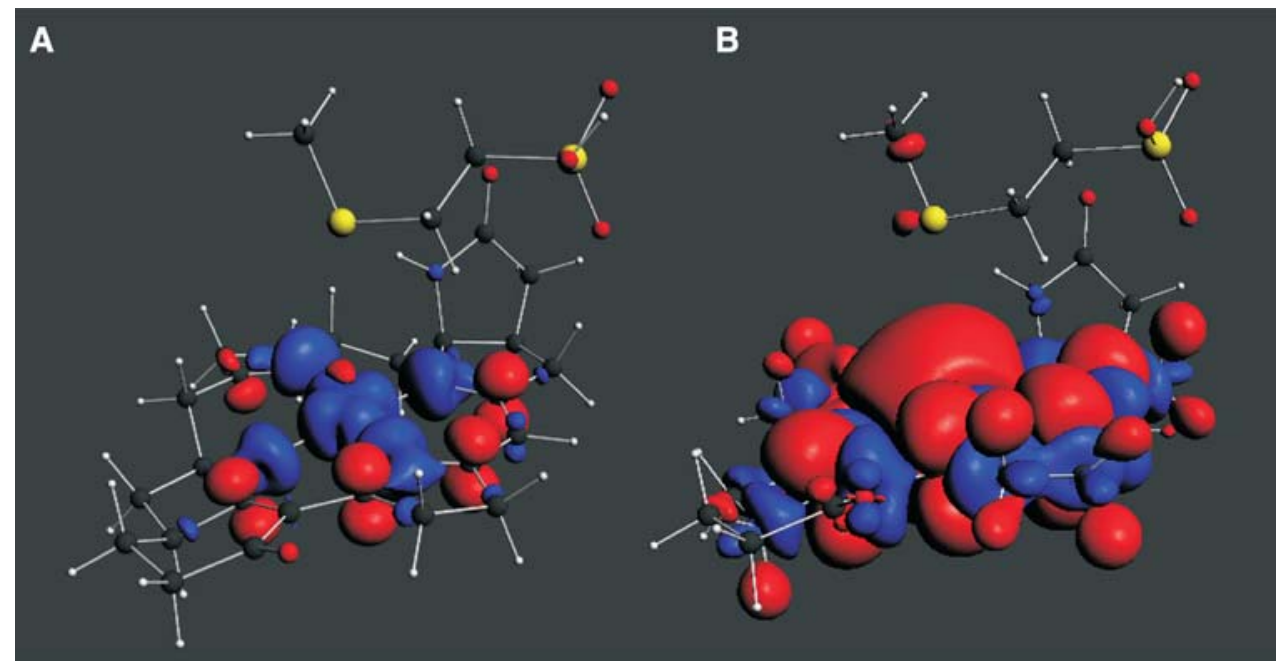

Fig. 7 Spin density plots (blue, positive; red, negative) of the DFT model for $\mathrm{MCR}_{\text {red } 1 \mathrm{~m}}$ at the level of (a) 0.001 and (b) 0.0001 . Note the small negative spin density of the methyl carbon of $\mathrm{CH}_{3}-\mathrm{S}-\mathrm{CoM}$. Selected bond lengths: $\mathrm{Ni}-\mathrm{S}=3.94 \AA, \mathrm{Ni}-\mathrm{N}_{\mathrm{A}}=2.13 \AA, \mathrm{Ni}-$ $\mathrm{N}_{\mathrm{B}}=2.01 \AA, \mathrm{Ni}-\mathrm{N}_{\mathrm{C}}=2.07 \AA, \mathrm{Ni}-\mathrm{N}_{\mathrm{D}}=2.01 \AA$; unpaired electron

yield the isotropic and the dipolar parts of the $\mathrm{HI}$ between ${ }^{13} \mathrm{C}$ on the labeled substrate and the $\mathrm{Ni}(\mathrm{I})$ center. These calculations were performed on the model system (in vacuum) shown in Fig. 7, which contains $\mathrm{F}_{430}$ (with hydrogen instead of side chains in positions $2,4,7,8,12,13,18)$ and $\mathrm{CH}_{3}-\mathrm{S}$ CoM. Optimizing the geometry of this structure shows that there is a weak but positive interaction between the $\mathrm{Ni}(\mathrm{I})$ ion and the thioether sulfur amounting to $-16.5 \mathrm{~kJ} / \mathrm{mol}$, with a long bond length of $0.394 \mathrm{~nm}$. Figure 7 reveals that this interaction is electronic in nature since $\mathrm{CH}_{3}-\mathrm{S}-\mathrm{CoM}$ has nonzero unpaired electron spin populations on sulfur $(\rho=+0.16 \%)$ and the methyl carbon $(\rho=-0.12 \%)$. The ${ }^{13} \mathrm{C}$-methyl group hyperfine coupling from DFT is $A^{\mathrm{cal}}\left({ }^{13} \mathrm{C}\right)$ $=-0.93+[-0.08,-0.03,0.10] \mathrm{MHz},[\alpha, \beta, \gamma]=[22,25$, $141]^{\circ}$, which is in general agreement with the experimentally obtained couplings of $A\left({ }^{13} \mathrm{C}\right)=-1.10+[-0.16,-0.16$, 0.33] MHz. According to DFT, the methyl-carbon spin density comprises an $s$-orbital contribution of $-0.02 \%$, and a $-0.10 \% p$-orbital contribution which corresponds to a ${ }^{13} \mathrm{C}$ hyperfine interaction contribution of $T_{p \text {-orbital }}=[0.1,0.1$, $-0.2] \mathrm{MHz}$ (orientated approximately along the $\mathrm{C}^{\text {methyl }}-\mathrm{S}$ bond). The remaining anisotropy comes from interaction between the ${ }^{13} \mathrm{C}$ nuclear spin moment and the spin density (distributed mainly on $\mathrm{F}_{430}$ ), given by $T_{\rho}=[-0.13,-0.13$, $0.26] \mathrm{MHz}{ }^{1}$ Both contributions have different axis orientations and (significantly) an opposite sign, so, when

\footnotetext{
$\overline{1}$ The dipolar part $T_{\rho}$ can be estimated by either performing a pointdipole calculation using Eqs. $3 \mathrm{a}$ and $3 \mathrm{~b}$ and the 76 DFT spin populations given in Table S2, or by subtracting out the $p$-orbital contribution and assuming that it is orientated along the $\mathrm{C}-\mathrm{S}$ bond. Both methods give essentially the same result.
}

spin populations: $\mathrm{Ni}=90.5 \%, \mathrm{~N}_{\mathrm{A}}=4.2 \%, \mathrm{~N}_{\mathrm{B}}=4.1 \%, \mathrm{~N}_{\mathrm{C}}=5.8 \%$, $\mathrm{N}_{\mathrm{D}}=4.2 \%, \mathrm{~S}_{\text {thioether }}=0.16 \%, \mathrm{C}_{\text {methyl }}=-0.12 \%$. Note that the spin population total sums to $100 \%$ with both positive and negative contributions due to spin polarization, as can be appreciated from the blue and red densities on the figure

summed together, the largest principal axis no longer points closely along the $\mathbf{g}_{3}$ axis direction (see the Euler angles in Table 2). This is in contrast to the methyl protons described below with no $p$-orbital contribution. A close inspection of Fig. $3 \mathrm{c}$ shows that the largest ${ }^{13} \mathrm{C}$ methyl splitting is not along a $g$ value principal axis [which corresponds to the low $\left(\mathbf{g}_{\|}\right)$and high $\left(\mathbf{g}_{\perp}\right)$ ENDOR field positions].

There is a broad agreement between the largest methyl proton hyperfine couplings determined experimentally (Table $2, A_{\perp}=-0.5$ to $-0.6, A_{\|}=1.0-1.2 \mathrm{MHz}$ ) and by DFT $\left(A\left({ }^{1} \mathrm{H}\right)_{\max }=[-0.4,-0.3,0.82] \mathrm{MHz}\right)$. The larger experimental value would suggest a slightly shorter distance than given by the ADF calculations. A point-dipole calculation using Eqs. 3a and $3 \mathrm{~b}$ with the ADF model structure and total spin density distributed over the remaining 76 nuclei (see Table S2 for this input data) gives a good match to the experiment when the $\mathrm{Ni}-\mathrm{S}$ bond is reduced from $0.394 \mathrm{~nm}$ to $0.345-0.375 \mathrm{~nm}$ (by moving $\mathrm{CH}_{3}$-S-CoM toward $\mathrm{F}_{430}$ along the Ni-S vector). The corresponding shortest methyl $\mathrm{Ni}-\mathrm{H}$ bond distance is $0.535-0.565 \mathrm{~nm}$, in agreement with the previous lower limit obtained using Eqs. $3 \mathrm{a}$ and $3 \mathrm{~b}$ with experimental estimates of the spin populations $\left[r\left(\mathrm{Ni}-\mathrm{H}_{\text {methyl }}\right)>0.5 \mathrm{~nm}\right]$.

The relatively weak bond and the long bond distance are consistent with solution studies showing that free $\mathrm{Ni}(\mathrm{I}) \mathrm{F}_{430 \mathrm{M}}$ does not bind $\mathrm{CH}_{3}-\mathrm{S}-\mathrm{CoM}$, and the long distance explains why it could not be positively detected in XAS studies [23]. In the protein it would be expected that further complex stabilization occurs as a result of the binding of the negatively charged sulfonate group of $\mathrm{CH}_{3}$-S-CoM to a positively charged arginine side chain of the protein (as shown in the $\mathrm{X}$-ray structures containing 


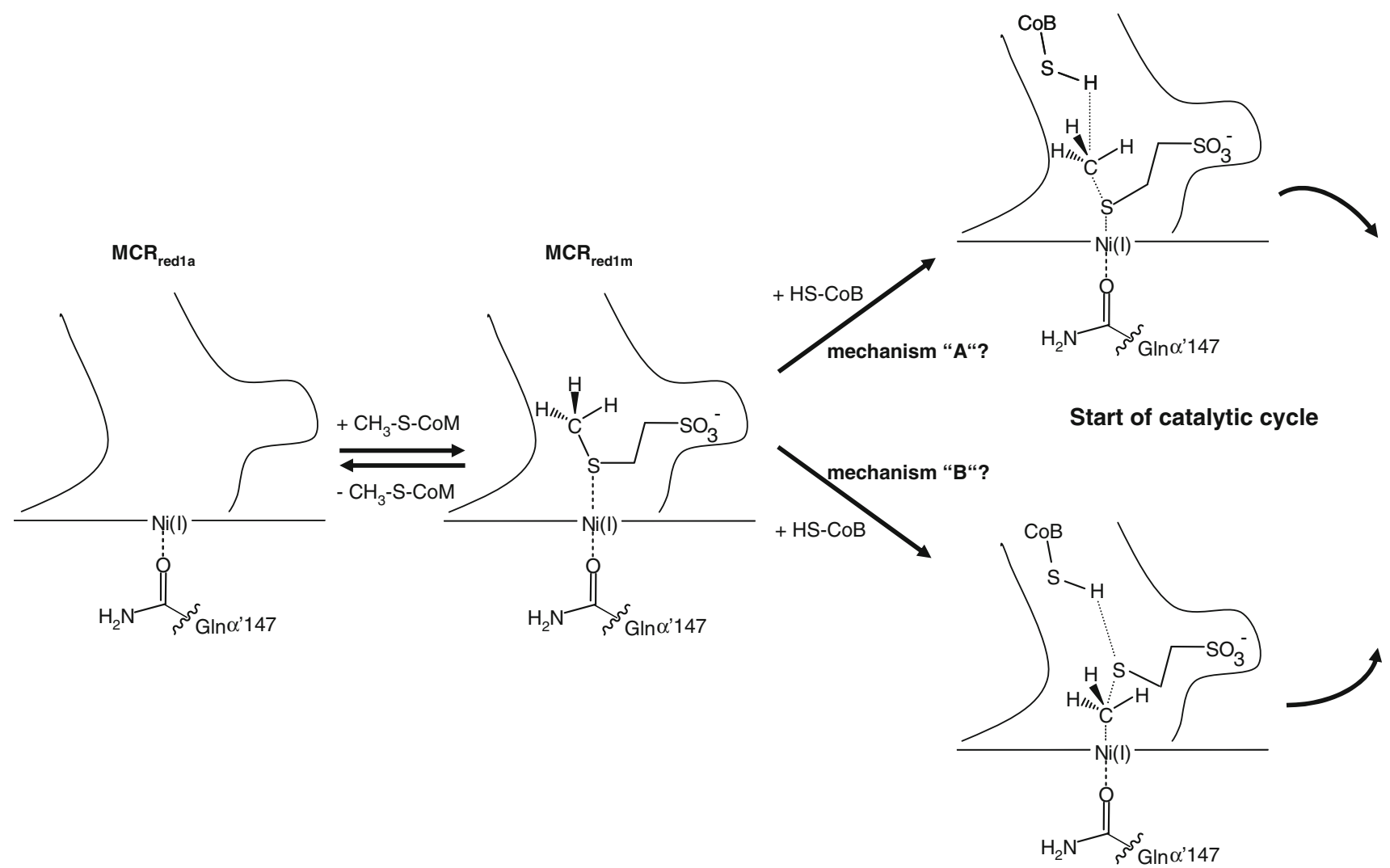

Fig. 8 Schematic of the coordination geometry of $\mathrm{CH}_{3}-\mathrm{S}-\mathrm{CoM}$ in $\mathrm{MCR}_{\text {red1m }}$ as derived from our EPR spectroscopic and DFT results. Upon the addition of $\mathrm{CH}_{3}-\mathrm{S}-\mathrm{CoM}$ to $\mathrm{MCR}$ in the $\mathrm{MCR}_{\text {red1a }}$ state, a complex between the $\mathrm{Ni}^{\mathrm{I}}$-center of $\mathrm{F}_{430}$ in MCR and the thioether

HS-CoM) and the steric constraints of the $\mathrm{F}_{430}$ environment, which help to place the substrate on the proximal side of $\mathrm{F}_{430}$ and directly above the $\mathrm{Ni}(\mathrm{I})$ ion.

How relevant is the weak $\mathrm{Ni}-\mathrm{S}$ coordination in $\mathrm{MCR}_{\text {red1m }}$ for the next steps in the catalytic cycle? The ordered two-substrate kinetics indicate that $\mathrm{MCR}_{\text {red1m }}$ has a higher affinity for the binding of the second substrate HS$\mathrm{CoB}$ than $\mathrm{MCR}_{\text {red1a }}$. Once HS-CoB is added to $\mathrm{MCR}_{\text {red } 1 \mathrm{~m}}$ the catalytic process starts, and-so far-no further intermediates have been observed before the formation of the final products, methane and the heterodisulfide CoM-S-S$\mathrm{CoB}$. At first sight, the weak $\mathrm{Ni}-\mathrm{S}$ coordination and the geometry of $\mathrm{CH}_{3}$-S-CoM with the methyl group pointing away from the Ni center reported here for $\mathrm{MCR}_{\mathrm{red} 1 \mathrm{~m}}$ would be consistent with the geometrical and stereoelectronic requirements of mechanism "A" or the newly proposed mechanism "C." For an $\mathrm{SN}_{2}$-like attack of $\mathrm{Ni}(\mathrm{I})$ on the methyl carbon, as proposed in mechanism " $\mathrm{B}$," a rotation around the $\mathrm{CH}_{3} \mathrm{~S}_{-}-\mathrm{CH}_{2}(\beta)$ bond of $\mathrm{CH}_{3}-\mathrm{S}-\mathrm{CoM}$, which turns the $\mathrm{CH}_{3}$-group towards the $\mathrm{Ni}$ with concomitant loss of the (weak) Ni-S coordination energy, would be required first.

Nevertheless, we hesitate to speculate about the implications of our findings on $\mathrm{MCR}_{\mathrm{red} 1 \mathrm{~m}}$ for the mechanism of sulfur atom of the substrate is formed. Also shown are the two mechanisms "A" and "B" that have been proposed for the actual bond-breaking step which follows the addition of HS-CoB. Mechanism " $C$ " proposed by Duin and McKee is not explicitly shown here

the subsequent bond-breaking steps, because results (to be reported separately) we obtained for the $\mathrm{MCR}_{\text {red2 }}$ species indicate that binding of the second substrate HS-CoB may induce a major structural change in the active site. The recent discovery of an MCR state that contains a Ni-hydride in its active site, which is formed upon the addition of HS-CoM and HS-CoB (called MCR $_{\text {red2a }}$ due to its almost axial $g$-tensor), and the existence of the $\mathrm{MCR}_{\text {red2r }}$ state induced simultaneously (called $\mathrm{MCR}_{\text {red2r }}$ due to its rhombic $g$-tensor) also suggest that larger structural rearrangements of the protein are possible when HS-CoB binds [62, 63].

Furthermore, the overall broad linewidths in the ENDOR spectra of Fig. 3 point toward a substantial degree of structural freedom on the proximal side of $\mathrm{F}_{430}$ in $\mathrm{MCR}_{\mathrm{red} 1 \mathrm{~m}}$. Therefore, it cannot be excluded that the methyl group of $\mathrm{CH}_{3} \mathrm{SCoM}$ might reorient itself towards the nickel upon the binding of the second substrate.

\section{Conclusions}

As schematically shown in Fig. 8, the weak Ni-S coordination and the lower limit for the distance between $\mathrm{Ni}(\mathrm{I})$ and 
the S-methyl carbon determined in this study (along with the binding of the sulfonate group to the enzyme backbone [1]) determine the position of $\mathrm{CH}_{3}$-S-CoM in the active site of $\mathrm{MCR}_{\mathrm{red} 1 \mathrm{~m}}$. The S-methyl group points away from the nickel and has a large degree of structural freedom, which can be deduced from the observation of broad linewidths in ENDOR spectra. Since the irreversible part of the catalytic reaction is triggered only after $\mathrm{HS}-\mathrm{CoB}$ is added to the $\mathrm{MCR}_{\text {red } 1 \mathrm{~m}}$ state (center of Fig. 8), this state can be considered the first and, so far, only observable intermediate in the cycle of MCR (right hand side of Fig. 8). In view of the indirect evidence for a major structural change in the active site upon the binding of HS-CoB and the substantial degree of freedom found for the S-methyl group in this study, the question of the binding geometry of $\mathrm{CH}_{3} \mathrm{SCoM}$ with respect to the nickel center in the transition state of the bondbreaking step remains open.

Acknowledgments We thank the Swiss National Science Foundation (SNF), the Fonds der Chemischen Industrie, and the EPSRC and BBSRC for financial support. Dariush Hinderberger gratefully acknowledges a research scholarship (HI 1094/1-1) from the Deutsche Forschungsgemeinschaft (DFG).

Open Access This article is distributed under the terms of the Creative Commons Attribution Noncommercial License which permits any noncommercial use, distribution, and reproduction in any medium, provided the original author(s) and source are credited.

\section{References}

1. Thauer RK (1998) Microbiology 144:2377-2406

2. Thauer RK, Jungermann K, Decker K (1977) Bacteriol Rev 41:100-180

3. Ermler U, Grabarse W, Shima S, Goubeaud M, Thauer RK (1997) Science 278:1457-1462

4. Goubeaud M, Schreiner G, Thauer RK (1997) Eur J Biochem 243:110-114

5. Pelmenschikov V, Blomberg MRA, Siegbahn PEM, Crabtree RH (2002) J Am Chem Soc 124:4039

6. Pelmenschikov V, Siegbahn PEM (2003) J Biol Inorg Chem 8:653

7. Horng YC, Becker DF, Ragsdale SW (2001) Biochemistry 40:12875

8. Ghosh A, Wondimagegn T, Ryeng H (2001) Curr Opin Chem Biol 5:744

9. Jaun B, Pfaltz A (1986) J Chem Soc Chem Commun 1327

10. Grabarse W, Mahlert F, Duin EC, Goubeaud M, Shima S, Thauer RK, Lamzin V, Ermler U (2001) J Mol Biol 309:315

11. Goenrich M, Duin EC, Mahlert F, Thauer RK (2005) J Biol Inorg Chem 10:333-342

12. Duin EC, Signor L, Piskorski R, Mahlert F, Clay MD, Goenrich M, Thauer RK, Jaun B, Johnson MK (2004) J Biol Inorg Chem 9:563-576

13. Ermler U (2005) Dalton Trans 3451-3458

14. Hinderberger D, Piskorski RP, Goenrich M, Thauer RK, Schweiger A, Harmer J, Jaun B (2006) Angew Chem Int Ed 45:3602-3607
15. Kunz RC, Horng YC, Ragsdale SW (2006) J Biol Chem 281:34663-34676

16. Yang N, Reiher M, Wang M, Harmer J, Duin EC (2007) J Am Chem Soc 129:11028-11029

17. Dey M, Telser J, Kunz RC, Lees NS, Ragsdale SW, Hoffman BM (2007) J Am Chem Soc 129:11030-11032

18. Sauer A, Cohen H, Meyerstein D (1988) Inorg Chem 27:4578

19. Wondimagegn T, Ghosh A (2001) J Am Chem Soc 123:1543

20. Lin SK, Jaun B (1991) Helv Chim Acta 74:1725

21. Duin EC, McKee ML (2008) J Phys Chem B 112:2466-2482

22. Mahlert F, Grabarse W, Kahnt J, Thauer RK, Duin EC (2002) J Biol Inorg Chem 7:101-112

23. Duin EC, Cosper NJ, Mahlert F, Thauer RK, Scott RA (2003) J Biol Inorg Chem 8:141-148

24. Rospert S, Boecher R, Albracht SPJ, Thauer RK (1991) FEBS 291:371-375

25. Rospert S, Linder D, Ellermann J, Thauer RK (1990) Eur J Biochem 194:871-877

26. Bonacker LG, Baudner S, Mörschel E, Böcher R, Thauer RK (1993) J Biochem 217:587-595

27. Bradford MM (1976) Anal Biochem 72:248-254

28. Gunsalus RP, Romesser JA, Wolfe RS (1978) Biochemistry 17:2374-2377

29. Pfaltz A, Jaun B, Faessler A, Eschenmoser A, Jaenchen R, Gilles HH, Diekert G, Thauer RK (1982) Helv Chim Acta 65:828

30. Schweiger A, Jeschke G (2001) Principles of pulse electron paramagnetic resonance. Oxford University Press, Oxford

31. Gromov I, Shane J, Forrer J, Rakhmatoullin R, Rozentzwaig Yu, Schweiger A (2001) J Magn Reson 149:196-203

32. Davies ER (1974) Phys Lett A 47:1-2

33. Bennebroek MT, Schmidt J (1997) J Magn Reson 128:199-206

34. Epel B, Poppl A, Manikandan P, Vega S, Goldfarb D (2001) J Magn Reson 148:388-397

35. Höfer P, Grupp A, Nebenführ G, Mehring M (1986) Chem Phys Lett 132:279-282

36. Jeschke G, Rakhmatoullin R, Schweiger A (1998) J Magn Reson 131:261-271

37. Jeschke G, Schweiger A (1996) Mol Phys 88:355-383

38. Forrer J, Garcia-Rubio I, Schuhmann R, Tschaggelar R, Harmer J (2008) J Magn Reson 190:280-291

39. Stoll S, Schweiger A (2006) J Magn Reson 178:42-55 (see http://www.esr.ethz.ch)

40. Madi Z, Van Doorslaer S, Schweiger A (2002) J Magn Reson 154:181-191

41. Ahlrichs R, Bär M, Häser M, Horn H, Kölmel C (1989) Chem Phys Lett 162:165-169

42. Becke AD (1988) Phys Rev A 38:3098-3100

43. Perdew JP (1986) Phys Rev B 33:8822-8824

44. Universität Karlsruhe (2008) FTP directory /pub/jbasen at ftp://ftp.chemie.uni-karlsruhe.de/pub/jbasen. Last accessed 8th August 2008

45. Becke AD (1993) J Chem Phys 98:5648-5652

46. Lee C, Yang W, Parr RG (1988) Phys Rev B 37:785-789

47. Schäfer A, Huber C, Ahlrichs R (1994) J Chem Phys 100:5829

48. te Velde G, Bickelhaupt FM, van Gisbergen SJA, Fonseca Guerra C, Baerends EJ, Snijders JG, Ziegler T (2001) J Comput Chem 22:931-967

49. Hammer B, Hansen LB, Norskov JK (1999) Phys Rev B 59:7413

50. van Lenthe E, Baerends EJ, Snijders JG (1993) J Chem Phys 99:4597

51. Brown TG, Hoffman BM (1980) Mol Phys 39:1073-1109

52. Telser J, Horng YC, Becker DF, Hoffman BM, Ragsdale SW (2000) J Am Chem Soc 122:182-183

53. Finazzo C, Harmer J, Jaun B, Duin EC, Mahlert F, Thauer RK, Van Doorslaer S, Schweiger A (2003) J Biol Inorg Chem 8:586-593 
54. Harmer J, Finazzo C, Piskorski R, Bauer C, Jaun B, Duin EC, Goenrich M, Thauer RK, Van Doorslaer S, Schweiger A (2005) J Am Chem Soc 127:17744

55. Pöppl A, Kevan L (1996) J Phys Chem 100:3387-3394

56. Grimaldi S, MacMillan F, Ostermann T, Ludwig B, Michel H, Prisner T (2001) Biochemistry 40:1037-1043

57. Lendzian F, Rautter J, Käss H, Gardiner A, Lubitz W (1996) Ber Bunsen-Ges Phys Chem 100:2036-2040

58. Spoyalov AP, Hulsebosch RJ, Shochat S, Gast P, Hoff A (1996) Chem Phys Lett 263:715-720

59. Deligiannakis Y, Hanley J, Rutherford AW (1999) J Am Chem Soc 121:7653-7664
60. Hanley J, Deligiannakis Y, MacMillan F, Bottin H, Rutherford AW (1997) Biochemistry 36:11543-11549

61. Garcia MLS, Smith JAS (1983) J Chem Soc Perkin Trans II 1401-1408

62. Harmer J, Finazzo C, Piskorski R, Ebner S, Duin EC, Goenrich M, Thauer RK, Reiher M, Schweiger A, Hinderberger D, Jaun B (2008) J Am Chem Soc 130:10907-10920

63. Kern DI, Goenrich M, Jaun B, Thauer RK, Harmer J, Hinderberger D (2007) J Biol Inorg Chem 12:1097-1105 